\title{
Lactobacillus plantarum and Lactobacillus reuteri as Functional Feed Additives to Prevent Diarrhoea in Weaned Piglets
}

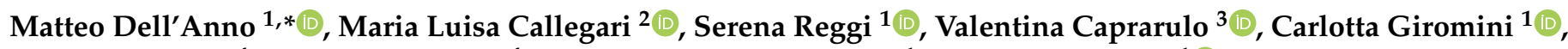 \\ Ambra Spalletta ${ }^{4}$, Simona Coranelli ${ }^{4}$, Carlo Angelo Sgoifo Rossi ${ }^{1}$ and Luciana Rossi ${ }^{1}$ (D) \\ 1 Department of Health, Animal Science and Food Safety "Carlo Cantoni” (VESPA), Università degli Studi di \\ Milano, 26900 Lodi, Italy; serena.reggi@unimi.it (S.R.); carlotta.giromini@unimi.it (C.G.); \\ carlo.sgoifo@unimi.it (C.A.S.R.); luciana.rossi@unimi.it (L.R.) \\ 2 Department for Sustainable Food Process, Università Cattolica del Sacro Cuore, 29122 Piacenza, Italy; \\ marialuisa.callegari@unicatt.it \\ 3 Department of Molecular and Translational Medicine (DMMT), Università degli Studi di Brescia, \\ 25123 Brescia, Italy; valentina.caprarulo@unibs.it \\ 4 Biotecnologie B.T. Srl, 06059 Todi, Italy; aspalletta@biotecnologiebt.it (A.S.); scoranelli@biotecnologiebt.it (S.C.) \\ * Correspondence: Matteo.DellAnno@unimi.it
}

Citation: Dell'Anno, M.; Callegari, M.L.; Reggi, S.; Caprarulo, V.; Giromini, C.; Spalletta, A.; Coranelli, S.; Sgoifo Rossi, C.A.; Rossi, L. Lactobacillus plantarum and

Lactobacillus reuteri as Functional Feed Additives to Prevent Diarrhoea in Weaned Piglets. Animals 2021, 11, 1766. https://doi.org/10.3390/ ani11061766

Academic Editor: Juan Florenñcio Tejeda Sereno

Received: 10 May 2021

Accepted: 8 June 2021

Published: 12 June 2021

Publisher's Note: MDPI stays neutral with regard to jurisdictional claims in published maps and institutional affiliations.

Copyright: (c) 2021 by the authors. Licensee MDPI, Basel, Switzerland. This article is an open access article distributed under the terms and conditions of the Creative Commons Attribution (CC BY) license (https:/ / creativecommons.org/licenses/by/ $4.0 /)$.
Simple Summary: Antimicrobial resistance is an increasing global concern. Effective alternatives that could replace and reduce antimicrobial treatments in farming have therefore become crucial for animal, human and environmental health. In swine farming, weaning is a stressful phase where piglets can develop multifactorial enteric disorders that require antibiotic treatments. Functional nutrition could thus represent a valuable alternative to reduce and tackle antibiotic resistance. This study assesses the effects of Lactobacillus plantarum and Lactobacillus reuteri on in-feed supplementation in weaned piglets. After weaning, piglets were allotted to four experimental groups fed a basal diet (CTRL) and a basal diet supplemented with $2 \times 10^{8} \mathrm{CFU} / \mathrm{g}$ of L. plantarum (PLA), L. reuteri and a combination of the two strains $(\mathrm{P}+\mathrm{R})$ for 28 days. Zootechnical performance and diarrhoea occurrence were recorded. Microbiological and serum metabolism analyses of faeces and blood samples were performed. Supplemented groups with lactobacilli showed a lower occurrence of diarrhoea and improved faecal consistency compared to the control. The PLA group registered the lowest diarrhoea frequency during the 28-day experimental period. The results suggest that dietary administration of L. plantarum and L. reuteri could prevent the occurrence of diarrhoea in weaned piglets.

Abstract: The effects of Lactobacillus plantarum and Lactobacillus reuteri and their combination were assessed in weaned piglets. Three hundred and fifty weaned piglets (Landrace $\times$ Large White), balanced in terms of weight and sex, were randomly allotted to four experimental groups ( 25 pens, 14 piglets/pen). Piglets were fed a basal control diet (CTRL, six pens) and a treatment diet supplemented with $2 \times 10^{8} \mathrm{CFU} / \mathrm{g}$ of L. plantarum (PLA, 6 pens), $2 \times 10^{8} \mathrm{CFU} / \mathrm{g}$ L. reuteri (REU, six pens) and the combination of both bacterial strains $\left(1 \times 10^{8} \mathrm{CFU} / \mathrm{g}\right.$ of L. plantarum combined with $1 \times 10^{8} \mathrm{CFU} / \mathrm{g}$ of L. reuteri, $\mathrm{P}+\mathrm{R}, 7$ pens $)$ for 28 days. Body weight and feed intake were recorded weekly. Diarrhoea occurrence was assessed weekly by the faecal score $(0-3$; considering diarrhoea $\geq 2)$. At 0 and 28 days, faecal samples were obtained from four piglets per pen for microbiological analyses and serum samples were collected from two piglets per pen for serum metabolic profiling. Treatments significantly reduced diarrhoea occurrence and decreased the average faecal score $(0.94 \pm 0.08 \mathrm{CTRL}, 0.31 \pm 0.08 \mathrm{PLA}, 0.45 \pm 0.08 \mathrm{REU}, 0.27 \pm 0.08 \mathrm{P}+\mathrm{R} ; p<0.05)$. The PLA group registered the lowest number of diarrhoea cases compared to other groups ( 20 cases CTRL, 5 cases PLA, 8 cases REU, 10 cases P+R; $p<0.01$ ). After 28 days, the globulin serum level increased in PLA compared to the other groups $(24.91 \pm 1.09 \mathrm{~g} / \mathrm{L}$ CTRL, $28.89 \pm 1.03 \mathrm{~g} / \mathrm{L}$ PLA, $25.91 \pm 1.03 \mathrm{~g} / \mathrm{L}$ REU, $25.31 \pm 1.03 \mathrm{~g} / \mathrm{L} \mathrm{P}+\mathrm{R} ; p<0.05)$. L. plantarum and L. reuteri could thus be considered as interesting functional additives to prevent diarrhoea occurrence in weaned piglets.

Keywords: Lactobacillus plantarum; Lactobacillus reuteri; probiotics; lactobacilli; functional nutrition; diarrhoea prevention; intestinal health; weaned pig 


\section{Introduction}

In livestock farming, effective alternatives to antibiotics that are able to promote health and prevent pathologies are urgently required to tackle antibiotic resistance [1-3], and replacing and reducing antibiotic treatments is one of the main targets of European policies [4]. This became even more important after the removal from the market of zinc oxide $(\mathrm{ZnO})$ as a veterinary therapeutic treatment $[5,6]$. This decision was taken due to the observed increase in heavy metal environmental pollution and scientific evidence showing that $\mathrm{ZnO}$ co-selects antibiotic-resistant bacteria $[7,8]$. $\mathrm{ZnO}$ has been used widely after the ban on antibiotics as a growth promoter over the last decade [6,9-11]. Alternatives to $\mathrm{ZnO}$ and antibiotics are thus required particularly during the weaning phase due to the high incidence of enteric disorders and multifactorial diseases such as post-weaning diarrhoea (PWD) [12,13]. The gastroenteric tract (GIT) is a complex environment where the mucosal chemical barrier, immune system, microbiota and epithelium all impact intestinal health $[14,15]$. Preserving intestinal health decreases the incidence of pathologies, optimises digestive processes and promotes animal performance. There is increased awareness regarding the role of diet, not only as a physiological requirement, but also in the enhancement of animal and human health and in the prevention of specific pathologies [16]. The modulation of intestinal microbiota by dietary approaches, such as the use of feed additives, is one of the most promising strategies to reduce the risk of pathologies in food-producing animals $[17,18]$.

Probiotics are functional feed additives defined as "live microorganisms which, when administered in adequate amounts, confer a health benefit on the host" [19]. Their potential mechanisms of action affect the intestinal microbial ecology through the manipulation of microbiota that lower the luminal $\mathrm{pH}$, the competitive inhibition of pathogen strains, the production of bacteriocins with antimicrobial proprieties and the stimulation of the host immune system [20]. Probiotic supplementation in animal diets helps prevent or treat a variety of intestinal disorders, although their mechanisms of actions are not completely known [21]. Lactic acid bacteria include over two-hundred species and subspecies of which Lactobacillus sp., Lactococcus sp., Spreptococcus sp. and Enterococcus sp. are used as probiotics for monogastric animals [22].

Lactobacillus plantarum is included in the European register of feed additives [8] as a preservative $(1 ; \mathrm{a})$, silage additive $(1 ; \mathrm{k})$, microorganism $(1 ; \mathrm{k})$ and gut flora stabilizer for chickens $(4 ; b)$. In several in vitro and in vivo studies, some strains of L. plantarum demonstrated a protective activity against epithelial intestinal barrier impairment, restoring the function of thigh junctions and reducing paracellular permeability [23,24]. In addition, L. plantarum CGMCC 1258 supplemented at $5 \times 10^{10} \mathrm{CFU} / \mathrm{kg}$ showed its positive effect in weaned piglets challenged with Escherichia coli K88, inhibiting diarrhoea and improving zootechnical performance [25]. In parallel, Lactobacillus reuteri was included in the EU feed additive register as a microorganism $(1 ; \mathrm{k})$ until its withdrawal in 2012 [8] due to a lack of the required documentation. This microorganism is not seen as being dangerous and no issues related to its safety were mentioned in the EU commission decision [26], since it is included in the Qualified Presumption of Safety (QPS) list of the European Union [27].

Lactobacillus reuteri $\mathrm{I} 5007$ has shown a potential to improve thigh junction expression in newborn piglets and has been found to have protective effects after lipo-polysaccharide (LPS)-induced stress in vitro [21]. L. reuteri strains TMW1.656 and LTH5794 produce reuteran which can decrease the adhesive capacity of ETEC E. coli [28]. However, several studies have shown the positive impact of various L. plantarum and L. reuteri strains on improving piglet performance, diarrhoea prevention, stress alleviation, immunity and microbiota modulation [29].

Since few papers have assessed the effects of L. plantarum and L. reuteri strains and their synergy through a wide range of bacterial combination and supplementation levels, more studies are required to clarify the functional proprieties and the optimal inclusion level of these two bacterial strains on diarrhoea prevention in weaned piglets. In addition, probiotics may interact with the host metabolism [30] through their hypocholesterolemic 
and liver protection effects [31,32]. Furthermore, the bacterial combination does not always result in a synergistic effect, also showing possible competition among probiotic strains [33]. The aim of the study was to evaluate L. plantarum, L. reuteri and whether their combined supplementation reflects synergistic or antagonistic effects on diarrhoea prevention, metabolic status and performance in weaned piglets.

\section{Materials and Methods}

\subsection{Species-Specific PCR}

Single colonies of L. plantarum and L. reuteri, isolated from swine, obtained from the Biotecnologie BT (Perugia, Italy) strain collection were cultured in De Man, Rogosa and Sharpe (MRS) medium for $24 \mathrm{~h}$ in anaerobiosis conditions at $37^{\circ} \mathrm{C}$. Bacterial strains were diluted in $20 \mu \mathrm{L}$ of lysis solution (microLYSIS ${ }^{\circledR}$ solution, Clent Life Science, Stourbridge, England) and thermically lysed following the manufacturer's instructions. After lysis, in order to confirm bacterial species, $2 \mu \mathrm{L}$ of extracted DNA was used for a PCR reaction through species-specific primers, following the protocol previously described by Torriani et al. [34] for L. plantarum and Song et al. [35] for L. reuteri. PCR reaction was performed with $17 \mu \mathrm{L}$ of PCR master mix (Client Life Science, Stourbridge, UK) and $0.5 \mu \mathrm{L}(0.25 \mu \mathrm{M})$ of specific primers. L. plantarum ATCC ${ }^{\circledR} 14917^{\mathrm{TM}}$ and L. reuteri DSM 20016 DNA were included as positive controls.

\subsection{Minimal Inhibitory Concentration (MIC)}

In order to assess the possible presence of antibiotic-resistant genes in L. plantarum and $L$. reuteri isolated strains, a minimal inhibitory concentration test was performed. MICs were assessed following ISO 10932 IDF 223 guidelines, adopting VetMIC Lact-1 (version 1) and VetMIC Lact-2 (version 2) (National Veterinary Institute, SVA) (Annex I and II). L. plantarum ATCC ${ }^{\circledR} 14917^{\mathrm{TM}}$ was included as a positive control. L. reuteri and L. plantarum were tested for 16 antibiotic molecules (gentamicin, kanamycin, streptomycin, neomycin, tetracycline, erythromycin, clindamycin, chloramphenicol, ampicillin, penicillin, vancomycin, quinupristin/dalfopristin, linezolid, trimethoprim, ciprofloxacin and rifampicin).

\subsection{Gastric Acid and Simulated In Vitro Digestion Resistance}

Bacterial cultures of L. reuteri and L. plantarum were diluted in MRS broth in order to obtain an optical density of 0.1 measured at $600 \mathrm{~nm}$ (V-630 UV-vis, Jasco Deutschland $\mathrm{GmbH}$, Germany). For the gastric acid tolerance test, both bacterial strains were incubated at different $\mathrm{pH}$ levels $(2,3,4,5,7$ and the control, i.e., medium in which the $\mathrm{pH}$ had not been changed), obtained by adding $\mathrm{HCl}(1 \mathrm{M})$ monitoring with a $\mathrm{pH}$ meter. To perform this assay, bacterial cultures were incubated for $1 \mathrm{~h}$ at $30^{\circ} \mathrm{C}$. Bacterial cultures were then diluted and plated on MRS agar using the overlay method [36]. Plates were incubated at $30{ }^{\circ} \mathrm{C}$ and the colonies were counted after $48 \mathrm{~h}$. Strain tolerances to in vitro-simulated gastrointestinal tract (GIT) conditions were evaluated according to Charteris et al. [37] and Jensen et al. [38], with minor adaptations. Three independent assays were performed for each strain. The MRS broth with lactobacillus inoculum were incubated at $37^{\circ} \mathrm{C}$ for $24 \mathrm{~h}$ in anaerobic conditions. To simulate the oral phase, a $10-\mathrm{mL}$ bacterial culture aliquot was added to $10 \mathrm{~mL}$ of a sterile electrolyte solution $\left(0.22 \mathrm{~g} / \mathrm{L} \mathrm{CaCl}_{2}, 16.2 \mathrm{~g} / \mathrm{L} \mathrm{NaCl}, 2.2 \mathrm{~g} / \mathrm{L}\right.$ $\mathrm{KCl}$ and $1.2 \mathrm{~g} / \mathrm{L} \mathrm{NaHCO}_{3}$ ) containing $2.0 \mathrm{~g} / \mathrm{L}$ pepsin (Sigma-Aldrich Co., Saint Louis, MO, USA) and the first sampling was performed. A gastric resistance assay was performed by adjusting the $\mathrm{pH}$ to 3.0 by the addition of $\mathrm{HCl}(1 \mathrm{M})$ to activate pepsinogen. The sampling was performed after $90 \mathrm{~min}$ of incubation at $37^{\circ} \mathrm{C}$ under stirring. A total of $2 \mathrm{~mL}$ was then sampled in two tubes for each strain and the cell pellets were obtained by centrifugation at $12,000 \mathrm{rpm}$ for $5 \mathrm{~min}$ at $4{ }^{\circ} \mathrm{C}$. In order to simulate duodenal shock phase, the bacterial pellet of one tube for each strain was resuspended in $2 \mathrm{~mL}$ of sterile saline solution $(16.30 \mathrm{~g}$ $\mathrm{K}_{2} \mathrm{HPO}_{4}, 0.9 \mathrm{~g} \mathrm{KH}_{2} \mathrm{PO}_{4}$ ) supplemented with $0.25 \mathrm{~g}$ of porcine bile extract (Oxgall, Merck, Darmstadt, Germany) and subsequently sampled after $10 \mathrm{~min}$ of incubation at $37^{\circ} \mathrm{C}$. To evaluate lactobacilli resistance to intestinal conditions, the bacterial pellet of the remaining 
tube of each strain was resuspended in $2 \mathrm{~mL}$ of sterile saline solution containing $0.075 \mathrm{~g}$ of porcine bile extract and $0.025 \mathrm{~g}$ of porcine pancreatin (Sigma-Aldrich Co., Saint Louis, MO, USA). The last sampling was performed after the incubation for $240 \mathrm{~min}$ at $37^{\circ} \mathrm{C}$. Bacterial viability was assessed by plate counting on MRS agar for each sampling point using the overlay method [36]. Plates were then incubated at $30^{\circ} \mathrm{C}$ for $48 \mathrm{~h}$, and visible colonies were enumerated.

\subsection{Small-Scale Fermentation and Freeze-Drying Resistance}

In order to optimise biomass production conditions for experimental trial dietary inclusion, a small-scale fermentation was adopted. A 3 L bioreactor was employed to produce bacterial biomass inoculating fresh L. reuteri and L. plantarum cultures in $2.5 \mathrm{~L}$ of MRS ( $\mathrm{pH}$ 5.2) supplemented with $2 \%$ of glucose maintained at $37^{\circ} \mathrm{C}$, stirred at $10 \mathrm{rpm}$, to harvest bacteria after 18 and $24 \mathrm{~h}$. Bacterial biomasses were weighted after centrifugation at $4{ }^{\circ} \mathrm{C}, 4800 \mathrm{rpm}$, for $25 \mathrm{~min}$. Viability was assessed by resuspending bacterial biomass and performing plate counting after $48 \mathrm{~h}$ of incubation under anaerobic conditions at $37^{\circ} \mathrm{C}$. Bacterial samples stored at $-80^{\circ} \mathrm{C}$ were freeze-dried and samples were heated for 1440 min with 0.2 mbar of pressure for the condenser. The biomass obtained and the vitality of lactobacilli strains were measured by weighting and plate counting, respectively.

\subsection{Bacterial Fermentation for Experimental Trial Batch Production}

Large-scale fermentations were adopted following the previously described conditions. A total of $3 \mathrm{~L}$ of fresh bacterial cultures were inoculated to $30 \mathrm{~L}$ of MRS (pH 5.2) supplemented with $1 \%$ of saccharose, maintained at $35^{\circ} \mathrm{C}$, and stirred at $10 \mathrm{rpm}$ for $24 \mathrm{~h}$. Biomass was harvested through centrifugation at $4200 \mathrm{rpm}, 4{ }^{\circ} \mathrm{C}$ for $45 \mathrm{~min}$ and cryopreservation solution $(43 \mathrm{~g} / \mathrm{L}$ Na citrate, $28.6 \mathrm{~g} / \mathrm{L}$ glucose, $28.6 \mathrm{~g} / \mathrm{L}$ saccharose, $28.6 \mathrm{~g} / \mathrm{L}$ milk powder and $28.6 \mathrm{~g} / \mathrm{L}$ ascorbic acid; $1: 2, w / v)$ was added before free-drying.

\subsection{Experimental Design, Animal Housing and Dietary Treatments}

The experimental trial was performed in accordance with European regulations [39] and approved by the Animal Welfare Organisation of University of Milan (OPBA authorisation $\left.n^{\circ} 09 / 2020\right)$. The in vivo trial was performed on a commercial farm free from pathologies included in the ex-list A of World Organization of Animal Health (OIE): atrophic rhinitis, Aujeszky disease, porcine reproductive respiratory syndrome, salmonellosis and transmissible gastroenteritis. Three-hundred and fifty piglets (Landrace $\times$ Large White) weaned at $28 \pm 2$ days and homogeneous in terms of sex (50\% male and $50 \%$ female) and weight $(7.48 \pm 1.07 \mathrm{~kg})$ were identified by individual ear tags and randomly divided into four experimental groups. Animals were allotted in 25 different pens (14 piglets/pen) in standardised environmental conditions $\left(27^{\circ} \mathrm{C}, 60 \%\right.$ relative humidity) for 28 days. After three days of an adaptation period when the animals were fed the same basal diet in order to enable them to overcome the typical post weaning fasting, piglets were assigned to four experimental groups and were fed ad libitum: the control group (CTRL: 84 piglets, 6 pens, $7.46 \pm 0.13 \mathrm{~kg}$ ) the basal diet; the L. plantarum treated group (PLA: 84 piglets, 6 pens, $7.49 \pm 0.12 \mathrm{~kg}$ ) basal diet supplemented with $2 \times 10^{8} \mathrm{CFU} / \mathrm{g}$ of Lactobacillus plantarum; the L. reuteri treated group (REU: 84 piglets, 6 pens, $7.62 \pm 0.12 \mathrm{~kg}$ ) basal diet plus $2 \times 10^{8} \mathrm{CFU} / \mathrm{g}$ of L. reuteri, and the L. plantarum and L. reuteri combination group $(\mathrm{P}+\mathrm{R}$ : 98 piglets, 7 pens, $7.36 \pm 0.11 \mathrm{~kg}$ ) fed basal diet plus $1 \times 10^{8} \mathrm{CFU} / \mathrm{g}$ of both bacterial strains. Treatments were balanced for each group. The $\mathrm{P}+\mathrm{R}$ group was characterised by one additional pen in order to include the entire trial room in the experimental design. All the diets were isoproteic and isoenergetic (Table 1) balanced using Plurimix System ${ }^{\circledR}$ software (Fabermatica, Cremona, Italy) in line with nutritional requirements for post-weaned piglets [40], and were provided by Ferraroni S.p.A. (Cremona, Italy). Considering the small amount of freeze-dried lactobacilli powder included, the bacterial strains were premixed with wheat flour to ensure a homogeneous dispersion before being added to the horizontal mixer. For the whole diet, $2 \%$ of the wheat meal was substituted with $2 \%$ of the experimental mix 
(wheat flour + bacterial strain in order to reach a concentration in the final preparation of $\left.2 \times 10^{8} \mathrm{CFU} / \mathrm{g}\right)$.

Table 1. Diet composition and principal chemical characteristics of experimental trial (\% as fed basis) divided by control (CTRL, fed basal diet) and treatment groups (TRT, fed basal diet supplemented with $2 \times 10^{8} \mathrm{CFU} / \mathrm{g}$ of Lactobacillus plantarum; $2 \times 10^{8} \mathrm{CFU} / \mathrm{g}$ of Lactobacillus reuteri and $1 \times 10^{8} \mathrm{CFU} / \mathrm{g}$ of both bacterial strains; PLA, REU and P+R, respectively).

\begin{tabular}{|c|c|c|}
\hline Ingredients, $\%$ as Fed Basis & CTRL & TRT \\
\hline Barley, meal & 26.84 & 26.84 \\
\hline Wheat, meal & 12.45 & 10.45 \\
\hline Corn, flakes & 11.63 & 11.63 \\
\hline Corn, meal & 10.00 & 10.00 \\
\hline Barley, flakes & 7.50 & 7.50 \\
\hline Soy protein concentrates & 5.00 & 5.00 \\
\hline Biscuits, meal & 4.00 & 4.00 \\
\hline Soybean, meal & 4.00 & 4.00 \\
\hline Dextrose monohydrate & 3.50 & 3.50 \\
\hline Sweet milk whey & 3.20 & 3.20 \\
\hline Herring, meal & 2.00 & 2.00 \\
\hline Plasma, meal & 2.00 & 2.00 \\
\hline Organic acids ${ }^{1}$ & 1.70 & 1.70 \\
\hline Coconut oil & 1.00 & 1.00 \\
\hline Soy oil & 1.00 & 1.00 \\
\hline Arbocel $^{2}$ & 0.70 & 0.70 \\
\hline Dicalcium phosphate & 0.60 & 0.60 \\
\hline L-Lysine & 0.60 & 0.60 \\
\hline Benzoic acid & 0.50 & 0.50 \\
\hline Vitamin and mineral premix ${ }^{3}$ & 0.50 & 0.50 \\
\hline DL-Methionine & 0.39 & 0.39 \\
\hline L-Threonine & 0.35 & 0.35 \\
\hline Sodium Chloride & 0.27 & 0.27 \\
\hline L-Valine $(96.5 \%)$ & 0.12 & 0.12 \\
\hline Enzymes 4 & 0.10 & 0.10 \\
\hline L-Tryptophan & 0.05 & 0.05 \\
\hline Experimental mix ${ }^{5}$ & - & 2.00 \\
\hline \multicolumn{3}{|c|}{ Calculated Chemical Composition ${ }^{6}$} \\
\hline Crude protein $(\%)$ & 17.00 & 17.00 \\
\hline Fat $(\%)$ & 4.20 & 4.20 \\
\hline Crude fibre (\%) & 2.90 & 2.90 \\
\hline Ashes (\%) & 5.20 & 5.20 \\
\hline $\mathrm{DE}^{7}(\mathrm{Mc} / \mathrm{Kg})$ & 3.92 & 3.83 \\
\hline
\end{tabular}

${ }^{1}$ Citric acid, fumaric acid, orthophosphoric acid, sorbic acid, calcium formate. ${ }^{2}$ Crude fibre concentrate (Rettenmaier \& Söhne GmbH + Co KG, Rosenberg, Germany). ${ }^{3}$ Additives per Kg: Vitamins, pro-vitamins and substances with similar effect. Retinyl Acetate 15,000 IU, Vitamin D3-Cholecalciferol $2000 \mathrm{IU}$, Vitamin E $120 \mathrm{mg}$, Vitamin B1 $2.0 \mathrm{mg}$, Vitamin B2 $4.8 \mathrm{mg}$, Vitamin B6 $3.4 \mathrm{mg}$, Calcium D-pantothenate $15.0 \mathrm{mg}$, Vitamin B12 $0.030 \mathrm{mg}$, Vitamin K3 $1.9 \mathrm{mg}$, Biotin $0.19 \mathrm{mg}$, Niacinamide $30.0 \mathrm{mg}$, Folic Acid $0.96 \mathrm{mg}$, Vitamin C $144 \mathrm{mg}$, Choline chloride $288 \mathrm{mg}$, Betaine hydrochloride $1000 \mathrm{mg}$, Compounds of trace elements Iron sulphate $115 \mathrm{mg}$, Manganese Oxide $48.0 \mathrm{mg}$, Zinc Oxide $96.1 \mathrm{mg}$, Copper Oxide $130 \mathrm{mg}$, Anhydrous Calcium Iodate $0.96 \mathrm{mg}$, Sodium Selenite $0.34 \mathrm{mg}$ ${ }^{4}$ 6-phytase, endo-1,4-beta-xylanase, endo-1,3(4)-beta-glucanase. ${ }^{5}$ Experimental mix was composed of wheat flour 00, and the respective bacterial strain according to dietary treatments: L. plantarum (PLA), L. reuteri (REU), L. plantarum and L. reuteri combination $(\mathrm{P}+\mathrm{R})$ in order to reach a final concentration of $2 \times 108 \mathrm{CFU} / \mathrm{g}$ in the complete diet. ${ }^{6}$ Calculation performed with Purimix System ${ }^{\circledR}$ software (Fabermatica, Cremona, Italy). ${ }^{7} \mathrm{DE}$ : digestible energy content estimated from NRC (2012).

Experimental diets were analysed in duplicate for lactobacilli viability by plate counting and principal nutrient content [41]: dry matter (DM), crude protein (CP), ether extract (EE), crude fiber (CF) and ash concentrations. DM was obtained by drying samples in pre-weighed aluminium jars through a forced air oven at $65^{\circ} \mathrm{C}$. $\mathrm{CP}$ was determined by the Kjeldahl method. EE was assessed by performing ether extraction in a Soxtec. CF was 
determined by the filtering bag method. Ash content was measured after incinerating samples in a muffle furnace at $550{ }^{\circ} \mathrm{C}$. The fatty acid profile of the experimental diets was analysed starting from a total lipid extraction and the fatty acid methyl esters were prepared according to Christie and Han [42]. The fatty acid analysis was carried out using gas chromatography (TRACE GC Ultra, Thermo Fisher Scientific, Rodano, Italy) fitted with an automatic sampler (AI 1300, Thermo Fisher Scientific) and flame ionization detector (FID). An RT-2560 fused silica capillary column $(100 \mathrm{~m} \times 0.25 \mathrm{~mm} \times 0.25 \mu \mathrm{m}$ film thickness; Restek, Milan, Italy) was used with a programmed temperature from $80^{\circ} \mathrm{C}$ to $180^{\circ} \mathrm{C}$ at $3{ }^{\circ} \mathrm{C} / \mathrm{min}$, then from $180^{\circ} \mathrm{C}$ to $250^{\circ} \mathrm{C}$ at $2.5^{\circ} \mathrm{C} / \mathrm{min}$, which was then held for $10 \mathrm{~min}$. The carrier gas was helium at $1.0 \mathrm{~mL} / \mathrm{min}$ with an inlet pressure of $16.9 \mathrm{psi}$. A quantitative procedure was used where $1 \mathrm{~mL}$ of internal standard $(1 \mathrm{mg} / \mathrm{mL}$ 23:0 methyl ester; $\mathrm{N}-23-\mathrm{M}$; Nu-Chek Prep Inc., Elysian, MN, USA) was added prior to methylation. The fatty acid methyl ester (FAME) contents were quantified by weight as a percentage of the total FAMEs. All analyses were performed in duplicate.

\subsection{Animal Performance, Diarrhoea Occurrence and Biological Sample Collection}

Body weight (BW) was recorded individually at day 0 (T0), day 7 (T1), day 14 (T2), day 21 (T3) and day 28 (T4). Feed intake was recorded weekly by measuring the feed refused for each pen, considering the pen as the experimental unit. Other performance parameters: average daily gain (ADG), average daily feed intake (ADFI) and feed conversion ratio (FCR) were calculated. Four piglets per pen were randomly selected for faecal sample collection and microbiological analysis (24 piglets CTRL, 24 piglets PLA, 24 piglets REU, 28 piglets $\mathrm{P}+\mathrm{R}$; balanced per weight and sex) for the entire experimental period.

Diarrhoea occurrence was recorded weekly by evaluating the faecal consistency which was given a faecal score: a four-level scale $(0=$ dried consistency, $1=$ soft consistency, $2=$ mild diarrhoea, $3=$ severe diarrhoea). Faecal colour was evaluated through a threelevel colour scale: 1 = yellowish, 2 = greenish, 3 = brown; considering $\geq 2$ as a normal score [12].

Blood samples were obtained from the jugular vein at $\mathrm{T} 0$ and $\mathrm{T} 4$ through vacuum tubes from two randomly selected piglets per pen, balanced in terms of weight and sex, maintained over time for the entire experimental period.

\subsection{Microbiological and $p H$ Evaluation of Faecal Samples}

Faecal samples were analysed for the total countable bacteria, lactic acid bacteria and coliform bacteria through three different types of culture media: Plate Count Agar (PCA), De Man, Rogosa and Sharpe Agar (MRS) and Violet Red Bile Broth Agar (VRBA), respectively. One gram of faecal sample was diluted and homogenised with $10 \mathrm{~mL}$ of sterile $0.9 \% \mathrm{NaCl}$ solution and centrifugated ( $3000 \mathrm{rpm}, 10 \mathrm{~min}$ ) to collect the supernatants. Samples were then serially diluted tenfold, and microorganisms were enumerated by plate counting after $24 \mathrm{~h}$ of incubation at $37^{\circ} \mathrm{C}$. The lactic acid/coliform bacteria ratio was calculated based on plate counting data from MRS and VRBA agar. The results were expressed as $\log _{10}$ of colony-forming units per gram of faeces $\left(\log _{10} \mathrm{CFU} / \mathrm{g}\right)$. Fresh faecal samples of $\mathrm{pH}$ of $\mathrm{T} 4$, diluted in $10 \mathrm{~mL}$ of $0.9 \% \mathrm{NaCl}$ solution and subsequently centrifugated, were measured on the supernatant through a $\mathrm{pH}$ meter.

\subsection{Serum Metabolites}

Serum samples were obtained by centrifugation ( $3000 \mathrm{rpm}, 15 \mathrm{~min}$ ) and analysed for the concentration of: total protein $(\mathrm{g} / \mathrm{L})$, albumin $(\mathrm{g} / \mathrm{L})$, globulin $(\mathrm{g} / \mathrm{L})$, albumin/globulin (A/G ratio), alanine aminotransferase (ALT-GPT; IU/L), glucose ( $\mathrm{mmol} / \mathrm{L})$, urea $(\mathrm{mmol} / \mathrm{L})$, creatinine $(\mu \mathrm{mol} / \mathrm{L})$, total bilirubin $(\mu \mathrm{mol} / \mathrm{L})$, total cholesterol $(\mathrm{mmol} / \mathrm{L})$, triglycerides $(\mathrm{mmol} / \mathrm{L})$, high-density lipoprotein (HDL; mmol/L), low-density lipoprotein (LDL; mmol/L), phosphorus $(\mathrm{mmol} / \mathrm{L})$ and magnesium $(\mathrm{mmol} / \mathrm{L})$ levels with a multiparametric autoanalyzer for clinical chemistry (ILab 650; Instrumentation Laboratory Company, Lexington, MA, USA) at $37^{\circ} \mathrm{C}$. Serum concentration of interleukins 3,6 and 10 were also quantified im- 
munoenzymatically using enzyme-linked immunosorbent assay (ELISA) kits specific for swine species according to the manufacturer's instructions (Bioassay Technology Laboratory, Shanghai, China), and concentrations were calculated by fitting the relative standard curves with CurveExpert 1.4 software.

\subsection{Statistical Analysis}

The results were analysed using a repeated-measures ANOVA using JMP 14 Pro ${ }^{\circledR}$ (SAS Inst. Inc., Cary, NC, USA). Zootechnical performance, faecal score data and faecal bacterial counts were evaluated using a full factorial model (Treatment: Trt, Time: Time, Interaction: Trt $\times$ Time). Data related to acid resistance, in vitro simulated digestion, blood metabolism and faecal $\mathrm{pH}$ at T4 were assessed through analysis of variance (ANOVA). Diarrhoea incidence was obtained by converting the faecal score data into a dichotomous variable (presence or absence) in order to evaluate observed frequencies through the Pearson's Chi-Squared test. Multiple comparisons among groups were evaluated by performing Tukey's Honest Significance Difference test (Tukey's HSD). The results were presented as least square means \pm standard errors (SE). The means were considered different when $p \leq 0.05$ and statistically tendent for $0.09 \leq p<0.05$.

\section{Results}

\subsection{Species-Specific PCR}

PCR reaction confirmed the expected fragment of $318 \mathrm{bp}$ for L. plantarum and $303 \mathrm{bp}$ for L. reuteri (Figures S1 and S2).

\subsection{Minimal Inhibitory Concentrations}

The results of the MIC concentrations tested revealed a bacterial susceptibility to a wide range of antibiotics (Table S1).

\subsection{Acid and Simulated In Vitro Digestion Resistance}

Bacterial strains exposed to a different $\mathrm{pH}$ range showed a statistically significant drop in viability at $\mathrm{pH} 2$, with $L$. plantarum and $L$. reuteri registering a bacterial count of $8.09 \pm 0.11$ and $9.00 \pm 0.02 \log _{10} \mathrm{CFU} / \mathrm{mL}$, respectively $(p<0.0001)$, compared to their relative controls at $\mathrm{pH} 7\left(9.60 \pm 0.08\right.$ and $10.79 \pm 0.02 \log _{10} \mathrm{CFU} / \mathrm{mL}$, respectively) (Figure 1). Regarding the simulated gastrointestinal digestion, both bacterial strains exhibited an optimal capacity to survive with each tested condition, including gastric juice, bile shock and intestinal juice, without registering any significant decrease in viability compared to their relative initial microbial charge (Figure 2).
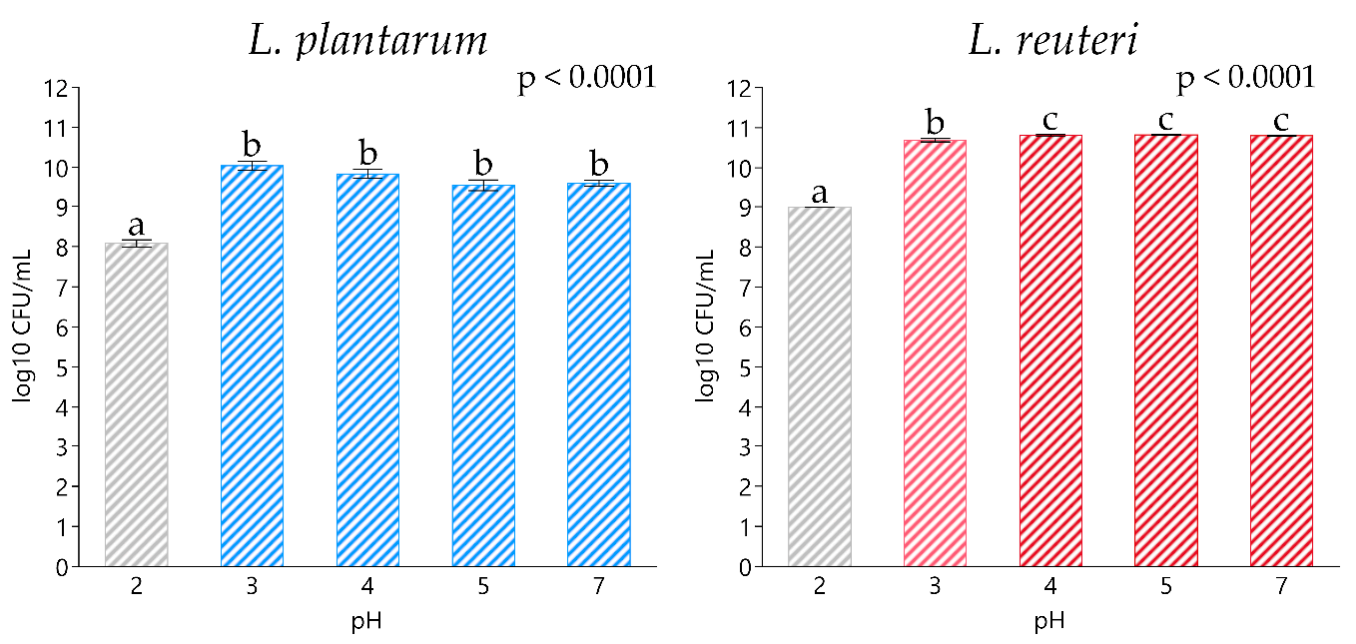

Figure 1. Acid resistance assay from $\mathrm{pH} 2$ to 7 for L. plantarum and L. reuteri. Data are expressed as least square means (LSMEANS) and standard errors (SE). ${ }^{a, b, c}$ Means with different superscript letters indicate statistically significant differences $(p<0.05)$. 
L. plantarum

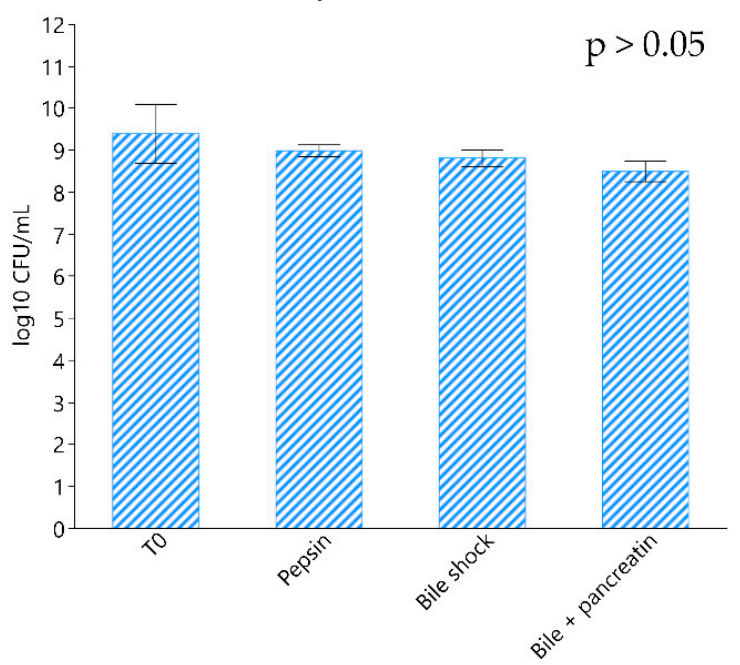

L. reuteri

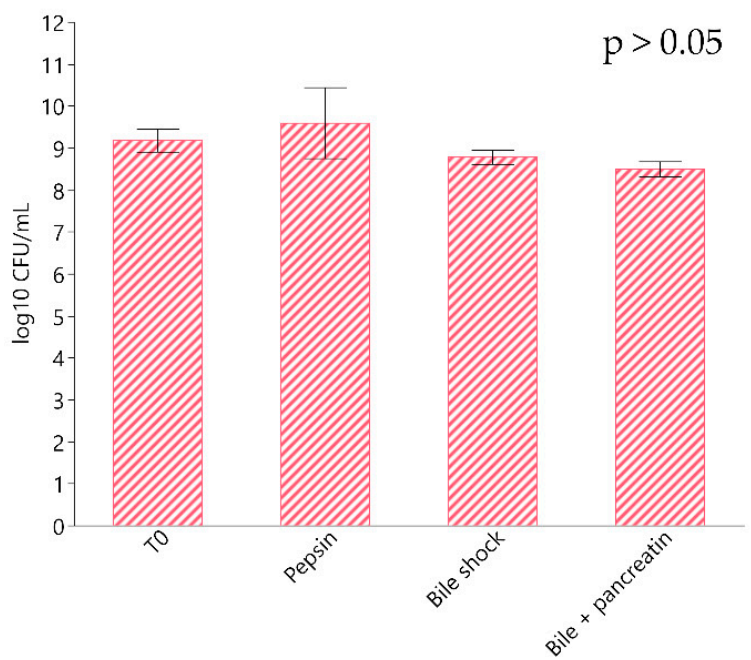

Figure 2. Simulated in vitro gastrointestinal digestion resistance of L. plantarum and L. reuteri. Data are expressed as least square means (LSMEANS) and standard errors (SE). T0 corresponds to the initial microbial charge measured before gastrointestinal environment simulation.

\subsection{Small-Scale Fermentation and Freeze-Drying Resistance}

The results of small-scale fermentations showed similar biomass gain and CFU/g viability for both strains considering 18 and $24 \mathrm{~h}$ of fermentation time and registering $2.25 \times 10^{11} \mathrm{CFU} / \mathrm{g}$ biomass for L. plantarum and $1.72 \times 10^{11} \mathrm{CFU} / \mathrm{g}$ biomass for L. reuteri after $24 \mathrm{~h}$ of fermentation (Table S2). Freeze-drying led to a loss in viability of about $1 \mathrm{log}$ considering the initial lactobacilli count (Table S3).

\subsection{Bacterial Fermentation for Experimental Trial Batch Production}

Large-scale fermentation performed with $30 \mathrm{~L}$ of bacterial culture produced 206.15 and $376.43 \mathrm{~g}$ of L. plantarum and L. reuteri biomass, respectively (Table S4). The freeze-dried bacteria were then used to prepare the experimental diets for a final concentration in feed of $2 \times 10^{8} \mathrm{CFU} / \mathrm{g}$.

\subsection{Evaluation of Experimental Diets}

Experimental diet evaluation of lactobacilli viability and principal nutrient content revealed a bacterial viability loss of $10 \%$ and nutrient concentrations in line with NRC [40] guidelines, thus fulfilling the nutritional requirements of weaned piglets. The inclusion of bacterial strains did not influence the nutrient profile of treatment groups (Table 2).

Table 2. Chemical composition of experimental diets divided by control (CTRL) and treatment groups (PLA, REU and P+R).

\begin{tabular}{ccccc}
\hline Analyte & CTRL & PLA & REU & P+R \\
\hline DM & 90.89 & 91.14 & 91.14 & 90.78 \\
CP & 16.34 & 17.01 & 16.38 & 16.64 \\
EE & 3.98 & 3.78 & 3.74 & 3.80 \\
CF & 3.60 & 3.65 & 3.34 & 3.40 \\
Ashes & 4.59 & 4.49 & 4.54 & 4.25 \\
\hline FA Composition (\% Total FAMEs) & \multicolumn{2}{c}{ CTRL } & \multicolumn{2}{c}{ TRT } \\
\hline Caproic acid, C6:0 & \multicolumn{2}{c}{0.04} \\
Caprylic acid, C8:0 & \multicolumn{2}{c}{1.00} & \multicolumn{2}{c}{1.10} \\
Capric acid, C10:0 & \multicolumn{2}{c}{0.121} \\
Undecanoic acid, C11:0 & \multicolumn{2}{c}{0.00} & 0.00 \\
\hline
\end{tabular}


Table 2. Cont.

\begin{tabular}{|c|c|c|}
\hline FA Composition (\% Total FAMEs) & CTRL & TRT \\
\hline Lauric acid, C12:0 & 10.85 & 11.69 \\
\hline Tridecanoic acid, C13:0 & 0.01 & 0.01 \\
\hline Myristic acid, C14:0 & 5.23 & 5.45 \\
\hline Mysticoleic acid, C14:1 & 0.01 & 0.01 \\
\hline Pentadecanoic acid, C 15:0 & 0.05 & 0.06 \\
\hline cis-10 Heptadecenoic acid, C 17:0 & 0.00 & 0.00 \\
\hline Stearic acid, C 18:0 & 15.17 & 14.95 \\
\hline Elaidic acid, C 18:1 n9t & 0.23 & 0.22 \\
\hline Oleic acid, C 18:1 n9c & 0.09 & 0.08 \\
\hline Linolelaidic acid, C18:2 n6t & 0.00 & 0.00 \\
\hline Linoleic acid, C 18:2 n6c & 4.34 & 4.07 \\
\hline$\gamma$-Linolenic acid, C 18:3 n6 & 0.05 & 0.04 \\
\hline$\alpha$-Linolenic acid, C18:3 n3 & 22.71 & 22.50 \\
\hline Arachidic acid, C 20:0 & 0.00 & 0.00 \\
\hline Cis-11 Eicosenoic acid, C20:1 & 34.42 & 33.92 \\
\hline Cis-11,14 Eicosenoic acid, C20:2 & 0.04 & 0.04 \\
\hline Cis-8,11,14 Eicosatrienoic acid, C20:3 n6 & 2.65 & 2.74 \\
\hline Cis-11,14,17 Eicosatrienoic acid, C20:3 n3 & 0.31 & 0.29 \\
\hline Arachidonic acid, C20:4 n6 & 0.43 & 0.40 \\
\hline $\begin{array}{c}\text { Cis-5,8,11,14,17 Eicosapentaenoic acid, } \\
\text { C20:5 n3 }\end{array}$ & 0.05 & 0.04 \\
\hline Heneicosanoic acid, C21:0 & 0.00 & 0.00 \\
\hline Behenic acid, C22:0 & 0.01 & 0.01 \\
\hline Erucic acid, C22:1 n9 & 0.02 & 0.02 \\
\hline Cis-13,16 Docosadienoic acid, C22:2 & 0.26 & 0.25 \\
\hline $\begin{array}{c}\text { Cis- } 4,7,10,13,16,19 \text { Docosahexaenoic acid, } \\
\text { C22:6 n3 }\end{array}$ & 0.02 & 0.02 \\
\hline Lignoceric acid; C24:0 & 0.25 & 0.23 \\
\hline Nervonic acid, C24:1 & 0.04 & 0.04 \\
\hline SFA & 38.64 & 39.36 \\
\hline MUFA & 23.52 & 23.25 \\
\hline PUFA & 37.83 & 37.39 \\
\hline
\end{tabular}

DM: dry matter; CP: crude protein; EE: ether extract; CF: crude fibre; FA: fatty acids; FAMEs: fatty acid methyl esters; SFA: saturated fatty acids, MUFA monounsaturated fatty acids, PUFA: polyunsaturated fatty acids. All values are expressed as percentage as fed basis (\%). CTRL: control group; PLA: treatment group supplemented with $2 \times 10^{8} \mathrm{CFU} / \mathrm{g}$ of L. plantarum; REU: treatment group supplemented with $2 \times 10^{8} \mathrm{CFU} / \mathrm{g}$ of L. reuteri; $\mathrm{P}+\mathrm{R}$ : treatment group supplemented with $2 \times 10^{8} \mathrm{CFU} / \mathrm{g}$ of $L$. plantarum and $L$. reuteri $(1: 1 \mathrm{w} / \mathrm{w})$; TRT: treatment group supplemented with $2 \times 10^{8} \mathrm{CFU} / \mathrm{g}$ of lactobacilli.

\subsection{Zootechnical Performance}

The results of individual BW recorded weekly showed no significant differences throughout the experimental period (Figure 3). The average BW of CTRL and PLA groups revealed a statistically significant tendency compared to $\mathrm{P}+\mathrm{R}$ considering the entire experimental period $(10.45 \pm 0.19 ; 10.42 \pm 0.17 ; 9.84 \pm 0.16 \mathrm{~kg}$, respectively; $p<0.09)$. In addition, the effect of treatments on ADG for the entire experimental period was significantly different for CTRL, REU and $\mathrm{P}+\mathrm{R}$ groups, which showed a reduced average gain for treated groups with $L$. reuteri (CTRL: $260 \pm 9$, REU: $220 \pm 8, \mathrm{P}+\mathrm{R}: 229 \pm 7 \mathrm{~g}$ /day; $p<0.05$ ). The ADFI of the supplemented groups decreased during the second week (7-14 days) of the study (CTRL: $490 \pm 24$, PLA: $281 \pm 24$; REU: $334 \pm 24$, P+R: $318 \pm 22$ g/day; $p<0.01$ ). The FCR parameter highlighted an increased ratio in P+R group compared to CTRL, PLA and REU during the first week (0-7 days; CTRL: $2.89 \pm 0.24$; PLA: $2.67 \pm 0.24$; REU: $2.67 \pm 0.24$; $\mathrm{P}+\mathrm{R}: 4.32 \pm 0.23 ; p<0.01)$. 

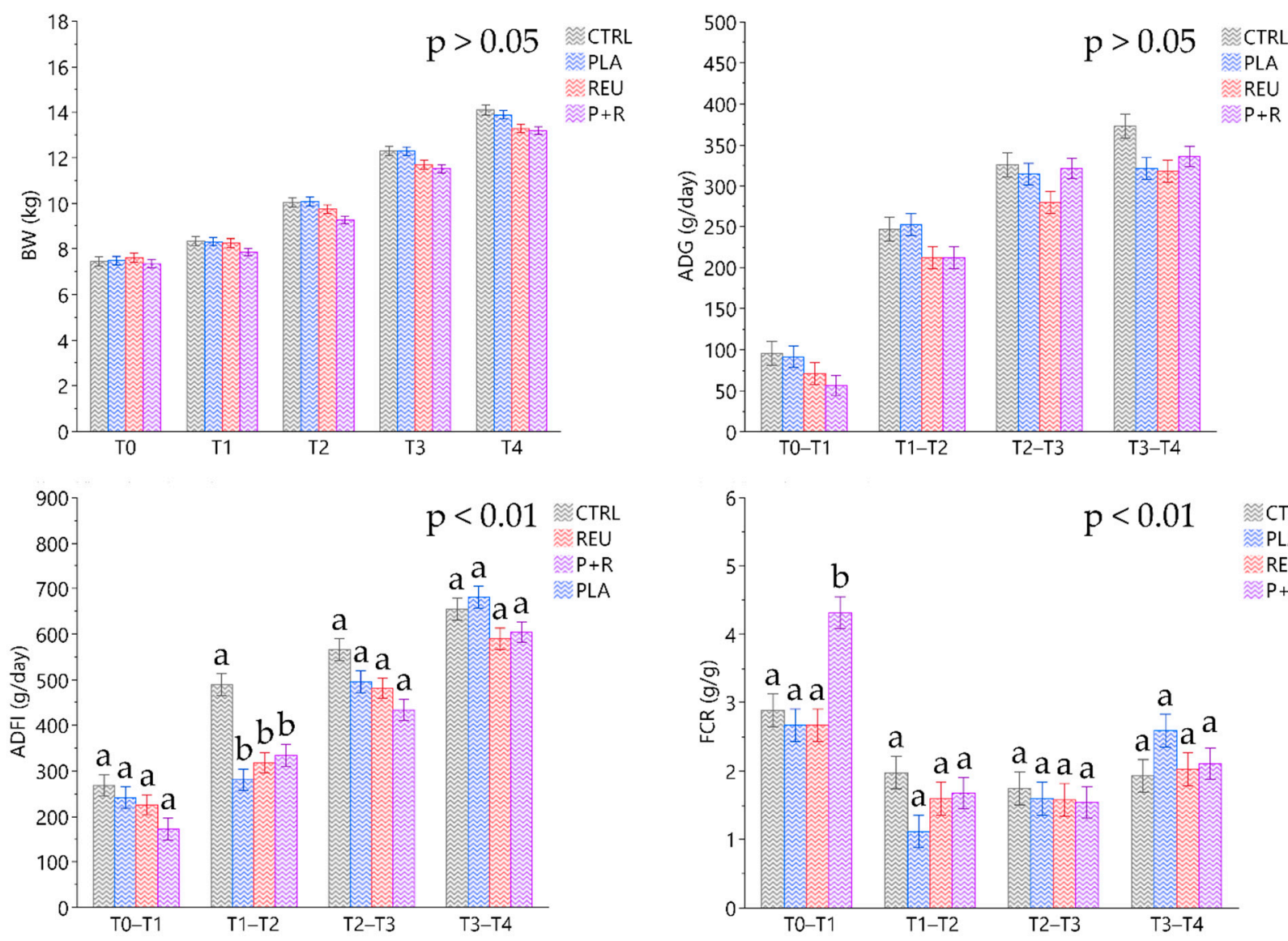

Figure 3. Zootechnical performance of control (CTRL) and treatment groups (PLA, REU and P+R) measured over 28 days of experimental trial. Data are expressed as least square means (LSMEANS) and standard errors of the means (SE); ${ }^{a}, \mathrm{~b}$ Means with different superscripts are significantly different among treatments $(p<0.01)$; Presented $p$-values indicate statistically significances of pairwise comparisons; BW: body weight; ADG: average daily gain; ADFI: average daily feed intake; FRC: feed conversion ratio; CTRL: control group; PLA: treatment group supplemented with $2 \times 10^{8} \mathrm{CFU} / \mathrm{g}$ of L. plantarum; REU: treatment group supplemented with $2 \times 10^{8} \mathrm{CFU} / \mathrm{g}$ of L. reuteri; P+R: treatment group supplemented with $2 \times 10^{8} \mathrm{CFU} / \mathrm{g}$ of L. plantarum and L. reuteri $(1: 1 w / w)$.

\subsection{Diarrhoea Occurrence}

Considering the entire experimental period, diarrhoea observed frequencies differed significantly among treatments $(p<0.01)$. The highest number of cases of diarrhoea (20 cases) was found in the CTRL group, while 13 and 10 cases were recorded in the REU and P+R groups, respectively. The lowest number of diarrhoea cases (five cases) was recorded in the PLA group (Figure 4). Data on diarrhoea incidence considering each timepoint showed a statistically significant increase in CTRL compared to the treated groups at T2 (CTRL: 6 cases, 25.00\%; PLA: 0 cases, $0.00 \%$; REU 0 cases, $0.00 \%$; P+R: 2 cases; $7.14 \% ; p<0.01$ ) (Figure 5A). At the last sampling point (T4), diarrhoea occurrence was significantly lower in the PLA and P+R groups (CTRL: 7 cases; 29.17\%; PLA: 0 cases, $0.00 \%$; REU: 6 cases, $25.00 \%$; P+R: 1 case; $3.57 \% ; p<0.01$ ). Average faecal scores of representative subgroups of evaluated piglets revealed a higher score for the CTRL group compared with PLA at T1 (CTRL: $1.17 \pm 0.13$; PLA: $0.40 \pm 0.13 ; p<0.01$ ) (Figure 5B). The average faecal score of CTRL after 14 days (T2) increased significantly compared with the treatment groups (CTRL: $1.31 \pm 0.13$; PLA: $0.34 \pm 0.13$; REU: $0.24 \pm 0.13$; P+R: $0.16 \pm 0.12$; $p<0.0001)$. At 21 days (T3), $\mathrm{P}+\mathrm{R}$ highlighted a lower score compared to the CTRL group (CTRL: $0.89 \pm 0.13 ; \mathrm{P}+\mathrm{R}: 0.18 \pm 0.13 ; p<0.05$ ). PLA and $\mathrm{P}+\mathrm{R}$ groups showed a significant decrease in average faecal score at the end of the trial compared to the CTRL group (CTRL: $1.16 \pm 0.14$; PLA: $0.13 \pm 0.14 ; \mathrm{P}+\mathrm{R}: 0.17 \pm 0.12 ; p<0.0001)$. 


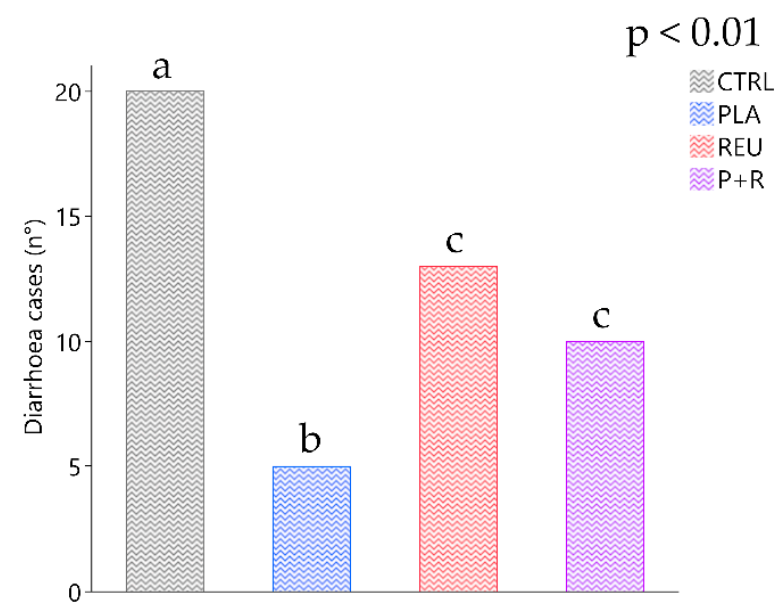

Figure 4. Total diarrhoea cases recorded during the 28-day trial for the control (CTRL) and treatment groups (PLA, REU and P+R). Data are expressed as the sum of recorded cases of diarrhoea, considering a faecal score $\geq 2$ diarrhoea; ${ }^{a, b, c}$ Means with different superscripts are significantly different among treatments $(p<0.01)$. CTRL: control group; PLA: treatment group supplemented with $2 \times 10^{8} \mathrm{CFU} / \mathrm{g}$ of L. plantarum; REU: treatment group supplemented with $2 \times 10^{8} \mathrm{CFU} / \mathrm{g}$ of L. reuteri; P+R: treatment group supplemented with $2 \times 10^{8} \mathrm{CFU} / \mathrm{g}$ of L. plantarum and L. reuteri $(1: 1, w / w)$.

A

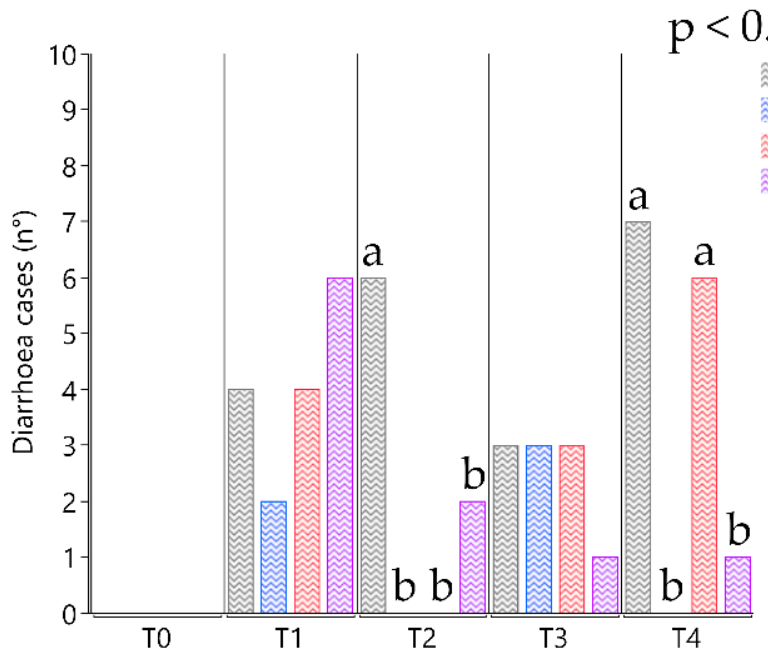

B

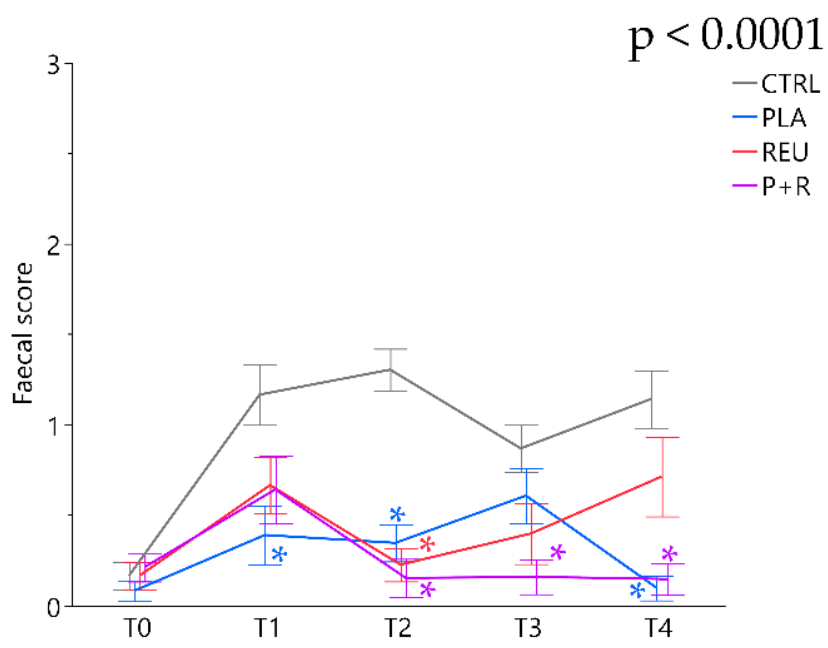

Figure 5. Number of diarrhoea cases recorded (A) and average faecal scores (B) during the 28-day trial for the control (CTRL) and treatment groups (PLA, REU and P+R). (A) Data are expressed as the sum of the recorded cases of diarrhoea, considering faecal score $\geq 2$ diarrhoea; ${ }^{a}, \mathrm{~b}$ Means with different superscripts are significantly different among treatments $(p<0.01)$. (B) Data are expressed as least square means (LSMEANS) and standard errors (SE); ${ }^{*}$ Means with asterisks are significantly different from the control group (CTRL, $p<0.0001)$. CTRL: control group; PLA: treatment group supplemented with $2 \times 10^{8} \mathrm{CFU} / \mathrm{g}$ of L. plantarum; REU: treatment group supplemented with $2 \times 10^{8} \mathrm{CFU} / \mathrm{g}$ of L. reuteri; P+R: treatment group supplemented with $2 \times 10^{8} \mathrm{CFU} / \mathrm{g}$ of L. plantarum and L. reuteri $(1: 1, w / w)$.

\subsection{Microbiological Analysis and Faecal $p H$}

Bacterial plate count results revealed no statistically significant difference among experimental groups at day 0 (T0) and after 28 days of the trial (T4) (Figure 6). However, a statistical tendency was observed for the lactic acid/coliform bacteria ratio at T4 comparing the CTRL and PLA groups $(1.08 \pm 0.10$ and $1.54 \pm 0.08 \mathrm{CFU} / g$, respectively; $p<0.09)$. 
Faecal $\mathrm{pH}$ measured at T4 revealed comparable averages among CTRL and treated groups (CTRL: $7.00 \pm$ 0.07; PLA: $7.02 \pm$ 0.08; REU: $7.24 \pm 0.10 ;$ P+R: $7.09 \pm 0.08$ ).
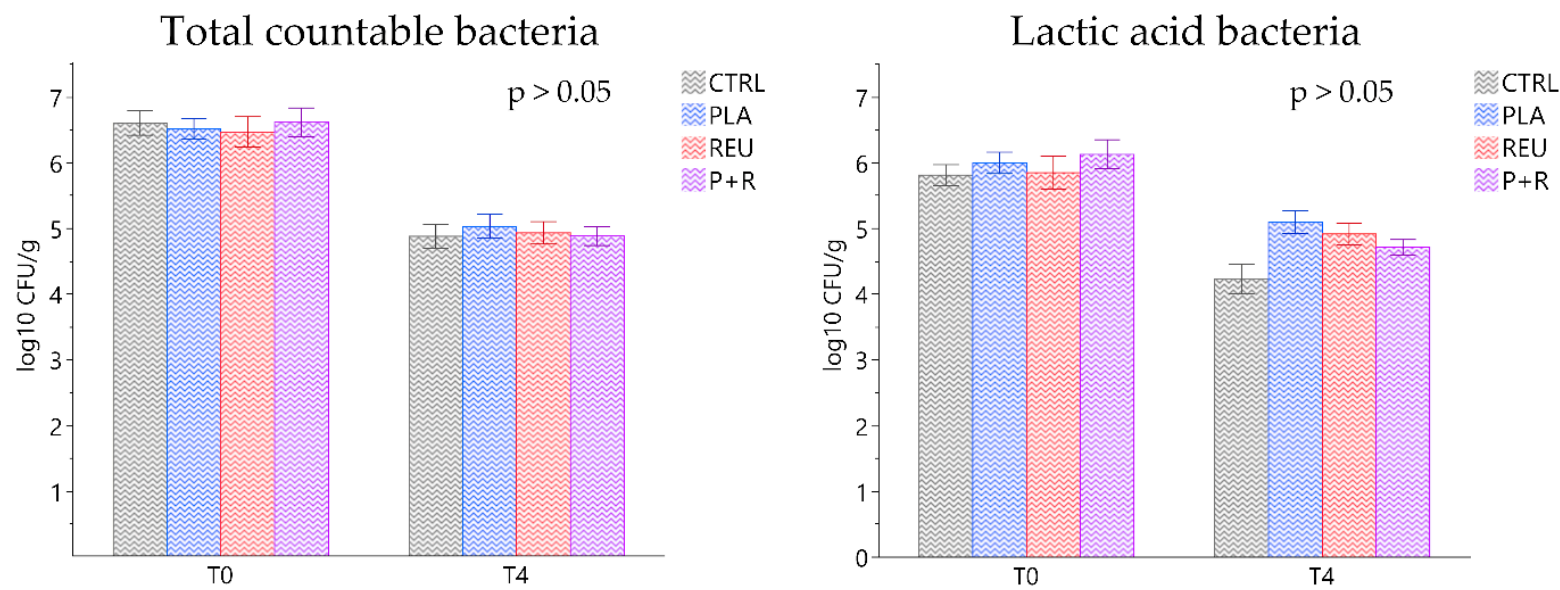

Coliform bacteria
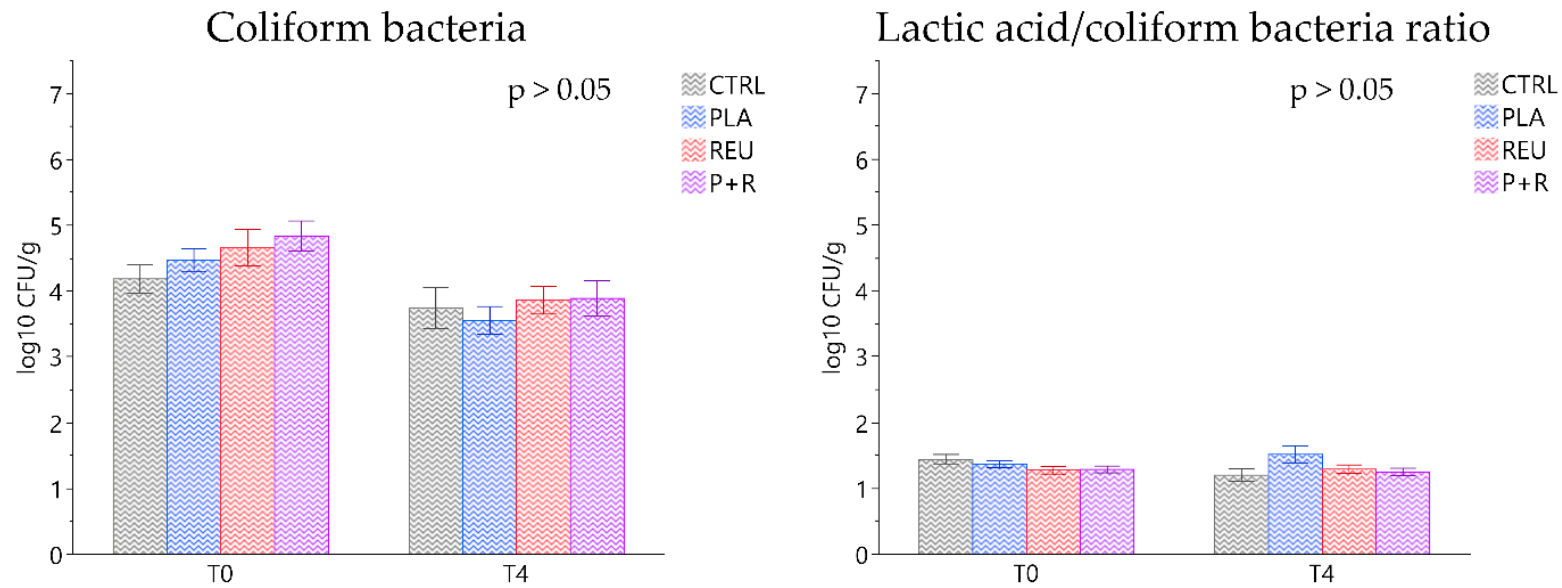

Figure 6. Faecal colonies of the principal bacterial groups (total countable bacteria, lactic acid bacteria, coliform bacteria and lactic acid/coliform ratio) for the control (CTRL) and treatment groups (PLA, REU and P+R) measured at the beginning (T0) and after 28 days of the trial (T4). Data are expressed as least square means (LSMEANS) and standard errors (SE). CTRL: control group; PLA: treatment group supplemented with $2 \times 10^{8} \mathrm{CFU} / \mathrm{g}$ of L. plantarum; REU: treatment group supplemented with $2 \times 10^{8} \mathrm{CFU} / \mathrm{g}$ of L. reuteri; P+R: treatment group supplemented with $2 \times 10^{8} \mathrm{CFU} / \mathrm{g}$ of L. plantarum and L. reuteri $(1: 1, w / w)$.

\subsection{Serum Metabolism}

The results of serum metabolites showed no statistically significant differences over time for all experimental groups at T0 (Table S5). After 28 days, the PLA group showed a statistically significant increase in globulin content compared to the other groups (Table 3; $p<0.05)$. Consequently, the albumin/globulin ratio of the PLA group was lower than the other experimental groups $(p<0.05)$. Alanine aminotransferase (ALT) decreased significantly in the PLA and REU groups compared to the other groups $(p<0.01)$. The phosphorous concentration was higher in the P+R compared to PLA and REU groups $(p<0.05)$. The PLA group showed a decreased magnesium content in serum compared to the other groups $(p<0.05)$. Total cholesterol was lower in PLA and REU compared to the other experimental treatments $(p<0.05)$. In fact, high density lipoproteins were lower in PLA and REU compared to CTRL and P+R treatments $(p<0.01)$. 
Table 3. Serum metabolites concentration at 28 days (T4) of in vivo trial, for the control (CTRL) and treatments groups (PLA, REU and P+R).

\begin{tabular}{|c|c|c|c|c|c|}
\hline Serum Metabolite & CTRL & PLA & REU & $\mathbf{P}+\mathbf{R}$ & $p$-Value \\
\hline Total protein content, g/L & $53.26 \pm 1.23$ & $54.85 \pm 1.15$ & $51.84 \pm 1.15$ & $52.09 \pm 1.15$ & 0.2576 \\
\hline Albumin, $\mathrm{g} / \mathrm{L}$ & $28.35 \pm 0.74$ & $26.00 \pm 0.70$ & $25.94 \pm 0.70$ & $26.77 \pm 0.70$ & 0.0916 \\
\hline Globulin, g/L & $24.91 \pm 1.09^{\mathrm{a}}$ & $28.89 \pm 1.03^{b}$ & $25.91 \pm 1.03^{\mathrm{a}}$ & $25.31 \pm 1.03^{\mathrm{a}}$ & 0.0455 \\
\hline Albumin/Globulin (A/G) & $1.16 \pm 0.05^{\mathrm{a}}$ & $0.92 \pm 0.05^{\mathrm{b}}$ & $1.06 \pm 0.05^{\mathrm{a}, \mathrm{b}}$ & $1.01 \pm 0.05^{\mathrm{a}, \mathrm{b}}$ & 0.0287 \\
\hline Urea, $\mathrm{mmol} / \mathrm{L}$ & $1.06 \pm 0.21$ & $1.42 \pm 0.20$ & $0.96 \pm 0.20$ & $0.89 \pm 0.20$ & 0.2452 \\
\hline $\begin{array}{c}\text { Alanine aminotransferase } \\
\text { (ALT-GPT), IU /L }\end{array}$ & $50.00 \pm 2.89^{a}$ & $38.22 \pm 2.73^{b}$ & $35.78 \pm 2.73^{b}$ & $46.00 \pm 2.73^{a, b}$ & 0.0034 \\
\hline Total bilirubin, $\mu \mathrm{mol} / \mathrm{L}$ & $1.84 \pm 0.13$ & $1.42 \pm 0.12$ & $1.45 \pm 0.12$ & $1.58 \pm 0.12$ & 0.1021 \\
\hline Glucose, $\mathrm{mmol} / \mathrm{L}$ & $6.36 \pm 0.47$ & $6.31 \pm 0.44$ & $5.36 \pm 0.44$ & $6.41 \pm 0.44$ & 0.2926 \\
\hline Phosphorus, mmol/L & $3.19 \pm 0.09^{\mathrm{a}, \mathrm{b}}$ & $2.87 \pm 0.08^{a}$ & $2.98 \pm 0.08^{\mathrm{a}}$ & $3.30 \pm 0.08^{b}$ & 0.0038 \\
\hline Magnesium, $\mathrm{mmol} / \mathrm{L}$ & $0.92 \pm 0.04^{\mathrm{a}}$ & $0.77 \pm 0.11^{b}$ & $0.79 \pm 0.12^{\mathrm{a}, \mathrm{b}}$ & $0.85 \pm 0.13^{\mathrm{a}, \mathrm{b}}$ & 0.0196 \\
\hline Creatinine, $\mu \mathrm{mol} / \mathrm{L}$ & $70.75 \pm 3.51$ & $77.33 \pm 3.31$ & $76.00 \pm 3.31$ & $81.10 \pm 3.31$ & 0.2175 \\
\hline Total cholesterol, mmol/L & $2.70 \pm 0.14^{\mathrm{a}}$ & $2.20 \pm 0.13^{b}$ & $2.27 \pm 0.13^{b}$ & $2.68 \pm 0.13^{\mathrm{a}}$ & 0.0195 \\
\hline $\begin{array}{l}\text { High density lipoprotein (HDL), } \\
\mathrm{mmol} / \mathrm{L}\end{array}$ & $1.08 \pm 0.06^{\mathrm{a}}$ & $0.77 \pm 0.06^{\mathrm{b}}$ & $0.81 \pm 0.06^{b}$ & $1.04 \pm 0.06^{\mathrm{a}}$ & 0.0011 \\
\hline $\begin{array}{l}\text { Low density lipoprotein (LDL), } \\
\mathrm{mmol} / \mathrm{L}\end{array}$ & $1.50 \pm 0.09$ & $1.26 \pm 0.09$ & $1.31 \pm 0.09$ & $1.52 \pm 0.09$ & 0.1173 \\
\hline Triglycerides, $\mathrm{mmol} / \mathrm{L}$ & $0.58 \pm 0.08$ & $0.83 \pm 0.07$ & $0.70 \pm 007$ & $0.60 \pm 0.07$ & 0.0764 \\
\hline Interleukin 3, pg/L & $17.80 \pm 1.98$ & $14.78 \pm 2.17$ & $17.28 \pm 2.17$ & $17.90 \pm 2.17$ & 0.7098 \\
\hline Interleukin 6, pg/L & $166.47 \pm 45.87$ & $152.65 \pm 45.87$ & $155.06 \pm 45.87$ & $166.48 \pm 45.87$ & 0.9941 \\
\hline Interleukin $10, \mathrm{pg} / \mathrm{L}$ & $10.67 \pm 2.13$ & $8.91 \pm 2.13$ & $8.49 \pm 2.13$ & $10.80 \pm 2.13$ & 0.8158 \\
\hline
\end{tabular}

Data are expressed as least square means (LSMEANS) \pm standard errors (SE). ${ }^{a, b}$ Means with different superscripts are significantly different among treatments $(p<0.05)$. CTRL: control group; PLA: treatment group supplemented with $2 \times 10^{8} \mathrm{CFU} / \mathrm{g}$ of L. plantarum; REU: treatment group supplemented with $2 \times 10^{8} \mathrm{CFU} / \mathrm{g}$ of L. reuteri; P+R: treatment group supplemented with $2 \times 10^{8} \mathrm{CFU} / \mathrm{g}$ of L. plantarum and $L$. reuteri $(1: 1, w / w)$.

\section{Discussion}

Weaning is a critical phase characterised by a high incidence of gastrointestinal disorders. Probiotics may support intestinal health during this particular phase. This study focused on the effects of the dietary supplementation of L. plantarum and L. reuteri and their combination on the performance, metabolic status and gut health in weaned piglets. Lactic acid bacteria need to be ingested when administered as probiotics. They therefore need to reach the intestinal environment in a viable state in order to exert their wide range of positive activities. Probiotic bacteria are thus required to pass through the gastric environment where the $\mathrm{pH}$ reaches 2.5 [43].

The results related to acid tolerance showed that both $L$. plantarum and L. reuteri tolerate $\mathrm{pH}$ levels above 2 without losing significant viability. In line with our study, Yun et al. [44] demonstrated that $L$. plantarum and $L$. reuteri were able to resist $\mathrm{pH}$ levels from 4 to 9 , meanwhile at $\mathrm{pH} 2$, both strains showed a similar survival reduction $(20 \%)$ after $6 \mathrm{~h}$ of incubation. Lukacova et al. [45] reported that more than $90 \%$ of L. plantarum strains need to survive at $\mathrm{pH} 3$ in order to act as probiotics.

In vitro simulated gastrointestinal tract transit tolerance is an important assay to evaluate the properties of probiotics. L. plantarum and L. reuteri strains showed an efficient ability to survive under each tested condition. In fact, L. plantarum and L. reuteri tolerate the gastric and small intestinal environment depending on the strain tested [38,46,47]. Bove et al. [48] evaluated the survival ability of L. plantarum WCFS1 in an oro-gastric-intestinal tract model, highlighting that this particular strain survives the entire digestion process. Our results suggest that L. plantarum and L. reuteri strains could be provided in feed and reach the intestinal environment without a significant viability loss, also without the need for other protection forms (e.g., microencapsulation).

The nutrient profile of experimental diets assessed by our chemical analyses was in line with post weaning piglet requirements following NRC guidelines [40]. Our experimental design considered a three-day adaptation period in order to enable piglets to adapt to the 
new environment and to be accustomed to feeding only on a solid diet, thus overcoming post-weaning fasting. Zootechnical performance is key to farm profitability and also an indirect index of animal health. Body weight showed a constant increase over the 28 days of our trial without significant differences among groups. Although the daily gain calculated for the 28 days was lower for REU and P+R than for CTRL, there were no differences considering all experimental groups for each timepoint (T1-T2-T3-T4). This thus highlighted that this slight reduction did not significantly impact the final body weight, ADG, ADFI and FCR of the animals. Other studies have shown a significant increase in body weight and average daily gain by including L. plantarum in the pig diet [25]. L plantarum supplemented at $10^{9} \mathrm{CFU} / \mathrm{d}$ showed an improved weight gain when administered for 60 days [49]. Bentancur et al. [50] orally administered $10^{9}$ CFU of $L$. plantarum CAM-6 from 21 to 49 days of age and found an increased daily gain and no differences in feed intake. In addition, L. reuteri strains supplementation have been shown to improve animal performance in weaned piglets [29,51]. Wang et al. [52] observed an increased feed intake and average daily gain with high doses of L. reuteri X-1 $\left(10^{11} \mathrm{CFU} / \mathrm{kg}\right)$. Although several studies have shown boosting activity related to animal performance, the results are not directly comparable due to the different bacterial genotypes tested, animal ages, particular probiotic combinations, different in-feed inclusion levels or disparate supplementation methods. Furthermore, in line with EFSA guidelines [53], zootechnical performance effects should be better clarified with a long-term study supplementing probiotics at higher dosages $\left(1 \times 10^{9} \mathrm{CFU} / \mathrm{g}\right)$.

Gastrointestinal disorders are a major problem in swine farming during the weaning phase, when diarrhoea is one of the most evident dysbiosis signs and one of the principal reasons for prescribing antibiotics. On the other hand, eubiosis represents a healthy gut that is achieved through a positive interaction between the host, microorganisms and the environment. Our results revealed a lower diarrhoea occurrence in the lactobacillisupplemented groups. The lowest diarrhoea cases were recorded in the L. plantarumsupplemented group (PLA). Over time, the lactobacilli-supplemented groups showed a lower faecal score, indicating an improved faecal consistency. The positive effect on diarrhoea was observed by administering different L. plantarum and L. reuteri strains to piglets individually. The prevention effects of L. plantarum on ETEC K88 have been observed in vitro and in vivo in a pig model through the stimulation of claudin-1, zonula occludens (ZO-1) and occludin expression, preventing epithelial barrier disruption $[25,54]$. Our results are in line with other studies where $L$. reuteri decreased diarrhoea incidence in piglets. In fact, $L$. reuteri supplemented at $2.4 \times 10^{5} \mathrm{CFU} / \mathrm{g}$ as a lactobacilli preparation complex decreased diarrhoea incidence by over $60 \%$ [55]. The in-feed supplementation of L. plantarum and L. reuteri confirms their positive contribution to eubiosis in the intestinal environment. In addition, these results suggest that single strains or a combination of these lactic acid bacteria could help prevent diarrhoea.

The bacterial plate count after weaning (T0) highlighted a high prevalence of lactic acid bacteria, and a reduction in this class was observed after 28 days (T4). In general, during the neonatal phase, lactobacilli and lactic acid bacteria are more common in piglets due to the consumption of maternal milk. They decrease in the post weaning phase frequently due to solid diet feeding [56]. During the trial, statistical differences in faecal viable bacterial counts were not detected among treatments and the control group. However, De Angelis et al. [57] found high viable lactobacilli in piglet faeces when $1 \times 10^{10} \mathrm{CFU} / \mathrm{pig} L$. plantarum 4.1 and L. reuteri $3 S 7$ were administered for 15 days. The lactic acid/coliform bacteria ratio can be considered as a practical index for efficacy tests of feed additives, aimed at promoting the immune defence. Higher values of the lactobacilli:coliform ratio are normally associated with increased resistance to intestinal disorders [58]. Even only a statistical tendency of PLA group was registered compared to CTRL for this index at T4. The whole lactobacilli supplemented groups showed a lactic acid/coliform bacteria ratio above 1.3. On the other hand, CTRL showed a similar prevalence of lactic acid and 
coliform bacteria, suggesting that lactic acid was more predominant than coliform bacteria in supplemented groups.

The serum metabolic profile was useful in evaluating animals' health and nutritional status, in order to clarify the possible interaction between bacteria and the host metabolism. Our results revealed that individual lactobacilli and their combined supplementation was safe without impairing animal metabolism, since all the values are in the normal range for pigs. The metabolic parameters showed higher levels of globulin which directly reduced the A/G ratio in PLA compared to the CTRL group. Globulins are mainly represented by immunoglobulins and are an important marker of immune system activity. Our results are in line with Dong et al. [59] who found a significant increase in globulin, with a simultaneous decrease in the A/G ratio after five weeks of L. plantarum GF103 supplementation. In addition, an increased concentration of IgA was observed by combining L. plantarum GF103 and Bacillus subtilis B27 [59]. The administration of microencapsulated L. plantarum and fructooligosaccharide blend has been found to increase plasma IgA and IgG concentrations in pigs [60]. Naqid et al. [61] observed that L. plantarum B2984 and lactulose dietary supplemented enhanced IgG production in response to Salmonella typhimurium infection in pigs. ALT can be exploited as a serum marker of liver damage, whose increase is related to cell membrane damage. Alanine aminotransferase is specific for liver tissues and is more effective in assessing a decrease in cell liver damage [62]. Although our results are in line with normal range for pigs [63-66], PLA and REU groups showed a significant reduction in serum ALT at 28 days suggesting a possible protective effect of L. plantarum and L. reuteri on liver cells. Fang et al. [32] showed that L. plantarum CMU995 supplementation decreased the ALT levels inhibiting alcohol-induced hepatitis. In line with our results, many probiotic species (L. acidophilus, L. bulgaricus, Bifidobacterium lactis, Streptococcus termophylus) demonstrated a protective effect on liver [67]. Phosphorous and magnesium are fundamental coenzymes and regulate many biochemical reactions in mammals. The P+R group had a higher $\mathrm{P}$ content after 28 days of supplementation with the lactobacilli combination. The magnesium serum concentration was lower in the PLA group than in other treatments. The interaction of dietary nutrients and the activity of microbiota are directly involved in mineral absorption [68]. P+R and PLA groups serum mineral concentrations suggest that L. plantarum administration could modulate mineral utilisation. Total cholesterol serum level is an index of the lipometabolic status, which includes the free and bounded forms of HDL [69]. The PLA and REU groups showed a significant reduction in total cholesterol, mainly due to the registered decrease of HDL concentration. L. plantarum and L. reuteri have been reported as positively contributing to cardiovascular diseases [70,71]. Certain probiotic strains could enhance faecal excretion of bile acids and resulting in a decrease of serum cholesterol concentration [72]. In line with this, L. plantarum 9-41-A significantly decreased hepatic cholesterol and TG levels when administered to rats fed a high-cholesterol diet [73]. Our results are likely due to the ability of the lactobacilli strain to modulate lipid metabolism, thereby preventing hypercholesterolemia.

\section{Conclusions}

Dietary supplementation of $2 \times 10^{8} \mathrm{CFU} / \mathrm{g}$ of L. plantarum and L. reuteri significantly reduced diarrhoea occurrence registering and had the lowest faecal score in our trial. $L$. plantarum had the lowest diarrhoea frequency compared to the other bacterial strains and their combinations. Lactobacilli supplementation did not influence animal performance, total faecal bacteria, faecal lactobacilli and coliform. Dietary lactobacilli inclusion did not reveal metabolic status alteration ascribable to a pathological status. In particular, $L$. plantarum significantly raised the globulin levels, suggesting a possible stimulation of the immune system. In conclusion, we believe that L. plantarum and L. reuteri are promising functional feed additives for preventing pig diarrhoea. More studies are required to enrich knowledge of these bacterial strains, to assess their effect for longer experimental periods, and to optimise their possible delivery systems. 
Supplementary Materials: The following are available online at https:/ / www.mdpi.com/article/10 .3390/ani11061766/s1, Figure S1: Agarose gel electrophoresis of L. plantarum PCR reaction products, Figure S2: Agarose gel electrophoresis of L. reuteri PCR reaction products, Table S1: MIC concentrations $(\mu \mathrm{g} / \mathrm{mL})$ obtained for L. plantarum and L. reuteri strains and cut-off values proposed from EFSA guidance on the assessment of bacterial susceptibility to antimicrobials of human and veterinary importance, Table S2: Obtained biomass from small-scale fermentations and viability of L. plantarum and $L$. reuteri, Table S3: Obtained biomass and relative viability of freeze-dried L. reuteri and $L$. plantarum, Table S4: Bacterial fermentation for experimental trial batch production, Table S5: Serum metabolites concentration at 0 days (T0) of in vivo trial, for the control (CTRL) and treatments groups (PLA, REU and P+R).

Author Contributions: Conceptualisation, M.D., A.S., S.C. and L.R.; methodology, M.D., S.R., A.S., S.C. and L.R.; formal analysis, M.D.; investigation: M.D., S.R., M.L.C., V.C., C.G., A.S. and S.C.; data curation: M.D., A.S., S.C. and S.R.; writing-original draft preparation, M.D.; writing-review and editing: M.D., M.L.C., C.G. and L.R.; visualisation: M.D.; supervision: L.R. and C.A.S.R.; project administration: L.R.; funding acquisition: L.R. All authors have read and agreed to the published version of the manuscript.

Funding: This research was funded by Lombardy Region and European Regional Development Fund (ERDF) under grant: Food Tech Project (ID: 203370).

Institutional Review Board Statement: The study was conducted according to the guidelines of the Declaration of Helsinki, and the experimental trial was approved by the Animal Welfare Organization of University of Milan (OPBA authorization $n^{\circ}$ 09/2020).

Data Availability Statement: The data presented in this study are available within the article and supplementary materials.

Acknowledgments: We are grateful to ProPhos Chemicals S.r.l. for project coordination and Ferraroni S.p.a. for providing the feed. Thanks are also due to Giancarlo Selmini who contributed to the in vivo trial diet formulation and Ernesto Bongiovanni who significantly supported the research group during the entire experimental period. The authors acknowledge the University of Milan for the support through the APC initiative.

Conflicts of Interest: The authors declare that they have no known competing financial interest or personal relationships that could have appeared to influence the work reported in this paper.

\section{References}

1. Arsène, M.M.; Davares, A.K.; Andreevna, S.L.; Vladimirovich, E.A.; Carime, B.Z.; Marouf, R.; Khelifi, I. The use of probiotics in animal feeding for safe production and as potential alternatives to antibiotics. Vet. World 2021, 14, 319. [CrossRef]

2. Ng, W.J.; Shit, C.-S.; Ee, K.Y.; Chai, T.T. Plant Natural Products for Mitigation of Antibiotic Resistance. In Sustainable Agriculture Reviews 49; Springer: Berlin/Heidelberg, Germany, 2021; pp. 57-91.

3. Tang, K.L.; Caffrey, N.P.; Nóbrega, D.B.; Cork, S.C.; Ronksley, P.E.; Barkema, H.W.; Polachek, A.J.; Ganshorn, H.; Sharma, N.; Kellner, J.D. Restricting the use of antibiotics in food-producing animals and its associations with antibiotic resistance in food-producing animals and human beings: A systematic review and meta-analysis. Lancet Planet. Health 2017, 1, e316-e327. [CrossRef]

4. Cormican, M.; Hopkins, S.; Jarlier, V.; Reilly, J.; Simonsen, G.; Strauss, R.; Vandenberg, O.; Zabicka, D.; Zarb, P.; Catchpole, M.; et al. ECDC, EFSA and EMA Joint Scientific Opinion on a list of outcome indicators as regards surveillance of antimicrobial resistance and antimicrobial consumption in humans and food-producing animals. EFSA J. 2017, 15. [CrossRef]

5. European Medicines Agency. EMA/394961/2017. European Medicines Agency, Questions and Answers on Veterinary Medicinal Products Containing Zinc Oxide to be Administered Orally to Food-Producing Species Outcome of a Referral Procedure under Article 35 of Directive 2001/82/EC (EMEA/V/A/118); EMA: London, UK, 2017.

6. Hejna, M.; Onelli, E.; Moscatelli, A.; Bellotto, M.; Cristiani, C.; Stroppa, N.; Rossi, L. Heavy-Metal Phytoremediation from Livestock Wastewater and Exploitation of Exhausted Biomass. Int. J. Environ. Res. Public Health 2021, 18, 2239. [CrossRef] [PubMed]

7. Bonetti, A.; Tugnoli, B.; Piva, A.; Grilli, E. Towards Zero Zinc Oxide: Feeding Strategies to Manage Post-Weaning Diarrhea in Piglets. Animals 2021, 11, 642. [CrossRef] [PubMed]

8. EU Commission. Regulation EC 1831/2003. of the European Parliament and of the Council, of 22 September 2003 on Additives for Use in Animal Nutrition (Text with EEA Relevance); EU Commission: Brussels, Belgium, 2003.

9. Hejna, M.; Gottardo, D.; Baldi, A.; Dell'Orto, V.; Cheli, F.; Zaninelli, M.; Rossi, L. Nutritional ecology of heavy metals. Animal 2018, 12, 2156-2170. [CrossRef] 
10. Hejna, M.; Moscatelli, A.; Onelli, E.; Baldi, A.; Pilu, S.; Rossi, L. Evaluation of concentration of heavy metals in animal rearing system. Ital. J. Anim. Sci. 2019, 18, 1372-1384. [CrossRef]

11. Hejna, M.; Moscatelli, A.; Stroppa, N.; Onelli, E.; Pilu, S.; Baldi, A.; Rossi, L. Bioaccumulation of heavy metals from wastewater through a Typha latifolia and Thelypteris palustris phytoremediation system. Chemosphere 2020, 241. [CrossRef]

12. Rossi, L.; Dell'Orto, V.; Vagni, S.; Sala, V.; Reggi, S.; Baldi, A. Protective effect of oral administration of transgenic tobacco seeds against verocytotoxic Escherichia coli strain in piglets. Vet. Res. Commun. 2014, 38, 39-49. [CrossRef]

13. Lu, C.W.; Wang, S.E.; Wu, W.J.; Su, L.Y.; Wang, C.H.; Wang, P.H.; Wu, C.H. Alternative antibiotic feed additives alleviate pneumonia with inhibiting ACE-2 expression in the respiratory system of piglets. Food Sci. Nutr. 2021, 9, 1112-1120. [CrossRef] [PubMed]

14. Chelakkot, C.; Ghim, J.; Ryu, S.H. Mechanisms regulating intestinal barrier integrity and its pathological implications. Exp. Mol. Med. 2018, 50, 1-9. [CrossRef]

15. Sarkar, A.; Yoo, J.Y.; Valeria Ozorio Dutra, S.; Morgan, K.H.; Groer, M. The association between early-life gut microbiota and long-term health and diseases. J. Clin. Med. 2021, 10, 459. [CrossRef]

16. Domínguez Díaz, L.; Fernández-Ruiz, V.; Cámara, M. The frontier between nutrition and pharma: The international regulatory framework of functional foods, food supplements and nutraceuticals. Crit. Rev. Food Sci. Nutr. 2020, 60, 1738-1746. [CrossRef]

17. Lallès, J.P.; Montoya, C.A. Dietary alternatives to in-feed antibiotics, gut barrier function and inflammation in piglets post-weaning: Where are we now? Anim. Feed Sci. Technol. 2021, 114836. [CrossRef]

18. Tomičić, Z.; Čabarkapa, I.; Čolović, R.; Đuragić, O.; Tomičić, R. Salmonella in the feed industry: Problems and potential solutions. J. Agron. 2018, 22, 2019.

19. Hori, T.; Matsuda, K.; Oishi, K. Probiotics: A Dietary Factor to Modulate the Gut Microbiome, Host Immune System, and Gut-Brain Interaction. Microorganisms 2020, 8, 1401. [CrossRef]

20. Guevarra, R.B.; Lee, J.H.; Lee, S.H.; Seok, M.J.; Kim, D.W.; Kang, B.N.; Johnson, T.J.; Isaacson, R.E.; Kim, H.B. Piglet gut microbial shifts early in life: Causes and effects. J. Anim. Sci. Biotechnol. 2019, 10,1-10. [CrossRef] [PubMed]

21. Yang, F.; Wang, A.; Zeng, X.; Hou, C.; Liu, H.; Qiao, S. Lactobacillus reuteri 15007 modulates tight junction protein expression in IPEC-J2 cells with LPS stimulation and in newborn piglets under normal conditions. BMC Microbiol. 2015, 15, 1-11. [CrossRef] [PubMed]

22. Śliżewska, K.; Chlebicz-Wójcik, A.; Nowak, A. Probiotic Properties of New Lactobacillus Strains Intended to Be Used as Feed Additives for Monogastric Animals. Probiotics Antimicrob. Proteins 2021, 13, 146-162. [CrossRef]

23. Lee, C.S.; Kim, S.H. Anti-inflammatory and anti-osteoporotic potential of lactobacillus plantarum A41 and L. fermentum SRK414 as probiotics. Probiotics Antimicrob. Proteins 2020, 12, 623-634. [CrossRef] [PubMed]

24. Gao, Y.; Liu, Y.; Ma, F.; Sun, M.; Song, Y.; Xu, D.; Mu, G.; Tuo, Y. Lactobacillus plantarum Y44 alleviates oxidative stress by regulating gut microbiota and colonic barrier function in Balb/C mice with subcutaneous D-galactose injection. Food Funct. 2021, 12, 373-386. [CrossRef] [PubMed]

25. Yang, K.; Jiang, Z.; Zheng, C.; Wang, L.; Yang, X. Effect of Lactobacillus plantarum on diarrhea and intestinal barrier function of young piglets challenged with enterotoxigenic Escherichia coli K88. J. Anim. Sci. 2014, 92, 1496-1503. [CrossRef]

26. EU Commission. Regulation EU 451/2012. COMMISSION IMPLEMENTING REGULATION (EU) No 451/2012 on the Withdrawal from the Market of Certain Feed Additives Belonging to the Functional Group of Silage Additives (Text with EEA Relevance); EU Commission: Brussels, Belgium, 2012.

27. EFSA BIOHAZ Panel; Koutsoumanis, K.; Allende, A.; Alvarez-Ordonez, A.; Bolton, D.; Bover-Cid, S.; Chemaly, M.; Davies, R.; De Cesare, A.; Hilbert, F.; et al. The list of QPS status recommended biological agents for safety risk assessments carried out by EFSA. EFSA J. 2021. [CrossRef]

28. Chen, X.Y.; Woodward, A.; Zijlstra, R.T.; Gänzle, M.G. Exopolysaccharides synthesized by Lactobacillus reuteri protect against enterotoxigenic Escherichia coli in piglets. Appl. Environ. Microbiol. 2014, 80, 5752-5760. [CrossRef]

29. Hou, C.; Zeng, X.; Yang, F.; Liu, H.; Qiao, S. Study and use of the probiotic Lactobacillus reuteri in pigs: A review. J. Anim. Sci. Biotechnol. 2015, 6, 14. [CrossRef] [PubMed]

30. Ghini, V.; Tenori, L.; Pane, M.; Amoruso, A.; Marroncini, G.; Squarzanti, D.; Azzimonti, B.; Rolla, R.; Savoia, P.; Tarocchi, M.; et al. Effects of Probiotics Administration on Human Metabolic Phenotype. Metabolites 2020, 10, 396. [CrossRef] [PubMed]

31. Khare, A.; Gaur, S. Cholesterol-Lowering Effects of Lactobacillus Species. Curr. Microbiol. 2020, 77, 638-644. [CrossRef]

32. Fang, T.; Guo, J.; Lin, M.; Lee, M.; Chen, Y.; Lin, W. Protective effects of Lactobacillus plantarum against chronic alcohol-induced liver injury in the murine model. Appl. Microbiol. Biotechnol. 2019, 103, 8597-8608. [CrossRef] [PubMed]

33. Chapman, C.; Gibson, G.; Rowland, I. In vitro evaluation of single- and multi-strain probiotics: Inter-species inhibition between probiotic strains, and inhibition of pathogens. Anaerobe 2012, 18, 405-413. [CrossRef]

34. Torriani, S.; Felis, G.E.; Dellaglio, F. Differentiation of Lactobacillus plantarum, L. pentosus, and L. paraplantarum by recA gene sequence analysis and multiplex PCR assay with recA gene-derived primers. Appl. Environ. Microbiol. 2001, 67, 3450-3454. [CrossRef]

35. Song, Y.L.; Kato, N.; Liu, C.X.; Matsumiya, Y.; Kato, H.; Watanabe, K. Rapid identification of 11 human intestinal Lactobacillus species by multiplex PCR assays using group-and species-specific primers derived from the 16S-23S rRNA intergenic spacer region and its flanking $23 S$ rRNA. FEMS Microbiol. Lett. 2000, 187, 167-173. [CrossRef] 
36. Warke, R.; Kamat, A.; Kamat, M.; Thomas, P. Incidence of pathogenic psychrotrophs in ice creams sold in some retail outlets in Mumbai, India. Food Control 2000, 11, 77-83. [CrossRef]

37. Charteris, W.; Kelly, P.; Morelli, L.; Collins, J. Development and application of an in vitro methodology to determine the transit tolerance of potentially probiotic Lactobacillus and Bifidobacterium species in the upper human gastrointestinal tract. J. Appl. Microbiol. 1998, 84, 759-768. [CrossRef]

38. Jensen, H.; Grimmer, S.; Naterstad, K.; Axelsson, L. In vitro testing of commercial and potential probiotic lactic acid bacteria. Int. J. Food Microbiol. 2012, 153, 216-222. [CrossRef]

39. Commission Directive EU 6/2010 amending Annex I to Directive 2002/32/EC of the European Parliament and of the Council as regards mercury, free gossypol, nitrites and Mowrah, Bassia, Madhuca (Text with EEA relevance). Off. J. Eur. Uni. 2002, 140, 1-10.

40. NRC. Nutrient Requirements of Swine, 7th ed.; National Research Council: Washington, DC, USA; The National Academies Press: Washington, DC, USA, 2012.

41. AOAC. Official Methods of Analysis, 21st ed.; Association of Official Analytical Chemists: Washington, DC, USA, 2019.

42. Christie, W.W.; Han, X. Lipid Analysis, Isolation, Separation, Identification and Lipidomic Analysis. Oily Press Lipid Libr. Ser. 2012, 181-211. [CrossRef]

43. Shewale, R.N.; Sawale, P.D.; Khedkar, C.; Singh, A. Selection criteria for probiotics: A review. Int. J. Probiotics Prebiotics 2014, $9,17$.

44. Yun, J.H.; Lee, K.B.; Sung, Y.K.; Kim, E.B.; Lee, H.G.; Choi, Y.J. Isolation and characterization of potential probiotic lactobacilli from pig feces. J. Basic Microbiol. 2009, 49, 220-226. [CrossRef] [PubMed]

45. Lukacova, D.; Karovicova, J.; Greifova, M.; Greif, G.; Sovcikova, A.; Kohajdova, Z. In vitro testing of selected probiotic characteristics of Lactobacillus plantarum and Bifidobacterium longum. J. Food Nutr. Res. 2006, 45, 77-83.

46. Singh, T.; Kaur, G.; Malik, R.; Schillinger, U.; Guigas, C.; Kapila, S. Characterization of Intestinal Lactobacillus reuteri Strains as Potential Probiotics. Probiotics Antimicrob. Proteins 2012, 4, 47-58. [CrossRef] [PubMed]

47. Vamanu, E. Effect of gastric and small intestinal digestion on lactic acid bacteria activity in a GIS1 simulator. Saudi J. Biol. Sci. 2017, 24, 1453-1457. [CrossRef]

48. Bove, P.; Russo, P.; Capozzi, V.; Gallone, A.; Spano, G.; Fiocco, D. Lactobacillus plantarum passage through an oro-gastro-intestinal tract simulator: Carrier matrix effect and transcriptional analysis of genes associated to stress and probiosis. Microbiol. Res. 2013, 168, 351-359. [CrossRef] [PubMed]

49. Suo, C.; Yin, Y.; Wang, X.; Lou, X.; Song, D.; Wang, X.; Gu, Q. Effects of Lactobacillus plantarum ZJ316 on pig growth and pork quality. BMC Vet. Res. 2012, 8, 1-12. [CrossRef] [PubMed]

50. Betancur, C.; Martínez, Y.; Merino-Guzman, R.; Hernandez-Velasco, X.; Castillo, R.; Rodríguez, R.; Tellez-Isaias, G. Evaluation of oral administration of Lactobacillus plantarum CAM6 strain as an alternative to antibiotics in weaned pigs. Animals 2020, 10, 1218. [CrossRef] [PubMed]

51. Wang, M.; Wu, H.; Lu, L.; Jiang, L.; Yu, Q. Lactobacillus reuteri promotes intestinal development and regulates mucosal immune function in newborn piglets. Front. Vet. Sci. 2020, 7, 42. [CrossRef] [PubMed]

52. Wang, S.; Yang, L.; Tang, X.; Cai, L.; Liu, G.; Kong, X.; Blachier, F.; Yin, Y. Dietary supplementation with high-dose Bacillus subtilis or Lactobacillus reuteri modulates cellular and humoral immunities and improves performance in weaned piglets. J. Food Agric. Environ. 2011, 9, 181-187.

53. EFSA; Rychen, G.; Aquilina, G.; Azimonti, G.; Bampidis, V.; Bastos, M.d.L.; Bories, G.; Chesson, A.; Cocconcelli, P.S.; Flachowsky, G. EFSA Panel on Additives and Products or Substances used in Animal Feed: Guidance on the assessment of the efficacy of feed additives. EFSA J. 2018, 16, e05274.

54. Wu, Y.; Zhu, C.; Chen, Z.; Chen, Z.; Zhang, W.; Ma, X.; Wang, L.; Yang, X.; Jiang, Z. Protective effects of Lactobacillus plantarum on epithelial barrier disruption caused by enterotoxigenic Escherichia coli in intestinal porcine epithelial cells. Vet. Immunol. Immunopathol. 2016, 172, 55-63. [CrossRef]

55. Huang, C.; Qiao, S.; Li, D.; Piao, X.; Ren, J. Effects of Lactobacilli on the performance, diarrhea incidence, VFA concentration and gastrointestinal microbial flora of weaning pigs. Asian-Australas J. Anim. Sci. 2004, 17, 401-409. [CrossRef]

56. Pieper, R.; Janczyk, P.; Schumann, R.; Souffrant, W. The intestinal microflora of piglets around weaning with emphasis on lactobacilli. Arch. Zootech. 2006, 9, 28-40.

57. De Angelis, M.; Siragusa, S.; Caputo, L.; Ragni, A.; Burzigotti, R.; Gobbetti, M. Survival and persistence of Lactobacillus plantarum 4.1 and Lactobacillus reuteri 3 S7 in the gastrointestinal tract of pigs. Vet. Microbiol. 2007, 123, 133-144. [CrossRef]

58. Castillo, M.; Martín-Orúe, S.M.; Manzanilla, E.G.; Badiola, I.; Martín, M.; Gasa, J. Quantification of total bacteria, enterobacteria and lactobacilli populations in pig digesta by real-time PCR. Vet. Microbiol. 2006, 114, 165-170. [CrossRef] [PubMed]

59. Dong, X.; Zhang, N.; Zhou, M.; Tu, Y.; Deng, K.; Diao, Q. Effects of dietary probiotics on growth performance, faecal microbiota and serum profiles in weaned piglets. Anim. Prod. Sci. 2014, 54, 616-621. [CrossRef]

60. Wang, W.; Chen, J.; Zhou, H.; Wang, L.; Ding, S.; Wang, Y.; Song, D.; Li, A. Effects of microencapsulated Lactobacillus plantarum and fructooligosaccharide on growth performance, blood immune parameters, and intestinal morphology in weaned piglets. Food Agric. Immunol. 2018, 29, 84-94. [CrossRef]

61. Naqid, I.A.; Owen, J.P.; Maddison, B.C.; Gardner, D.S.; Foster, N.; Tchórzewska, M.A.; La Ragione, R.M.; Gough, K.C. Prebiotic and probiotic agents enhance antibody-based immune responses to Salmonella Typhimurium infection in pigs. Anim. Feed Sci. Technol. 2015, 201, 57-65. [CrossRef] 
62. Belik, S.N.; Gorlov, I.F.; Slozhenkina, M.I.; Zlobina, E.Y.; Pavlenko, A.S. Morpho-functional state of the liver of the rats fed the rations with meat of the pigs grown with antimicrobials. Pak. Vet. J. 2015, 35, 325-328.

63. Klem, T.B.; Bleken, E.; Morberg, H.; Thoresen, S.I.; Framstad, T. Hematologic and biochemical reference intervals for Norwegian crossbreed grower pigs. Vet. Clin. Pathol. 2010, 39, 221-226. [CrossRef]

64. Friendship, R.M.; Lumsden, J.H.; McMillan, I.; Wilson, M.R. Hematology and Biochemistry Reference Values for Ontario Swine. Can. J. Comp. Med. 1984, 48, 390-393.

65. Caprarulo, V.; Hejna, M.; Giromini, C.; Liu, Y.; Dell'Anno, M.; Sotira, S.; Reggi, S.; Sgoifo-Rossi, C.A.; Callegari, M.L.; Rossi, L. Evaluation of Dietary Administration of Chestnut and Quebracho Tannins on Growth, Serum Metabolites and Fecal Parameters of Weaned Piglets. Animals 2020, 10, 1945. [CrossRef]

66. IZSLER. Parametri di Chimica Clinica: Valori Osservati in Suini di Diversa Età. Available online: https://www.izsler.it/pls/izs_ bs/v3_s2ew_consultazione.mostra_pagina?id_pagina=1494 (accessed on 18 March 2021).

67. Pereg, D.; Kotliroff, A.; Gadoth, N.; Hadary, R.; Lishner, M.; Kitay-Cohen, Y. Probiotics for patients with compensated liver cirrhosis: A double-blind placebo-controlled study. Nutrition 2011, 27, 177-181. [CrossRef] [PubMed]

68. Metzler, B.; Mosenthin, R. A review of interactions between dietary fiber and the gastrointestinal microbiota and their consequences on intestinal phosphorus metabolism in growing pigs. Asian-Australas. J. Anim. Sci. 2008, 21, 603-615. [CrossRef]

69. Wang, J.; Wu, C.; Feng, J. Effect of dietary antibacterial peptide and zinc-methionine on performance and serum biochemical parameters in piglets. Czech J. Anim. Sci. 2011, 56, 30-36. [CrossRef]

70. Li, C.; Nie, S.P.; Ding, Q.; Zhu, K.X.; Wang, Z.J.; Xiong, T.; Gong, J.; Xie, M.Y. Cholesterol-lowering effect of Lactobacillus plantarum NCU116 in a hyperlipidaemic rat model. J. Funct. Foods 2014, 8, 340-347. [CrossRef]

71. Taranto, M.P.; Medici, M.; Perdigon, G.; Holgado, A.R.; Valdez, G. Effect of Lactobacillus reuteri on the prevention of hypercholesterolemia in mice. J. Dairy Sci. 2000, 83, 401-403. [CrossRef]

72. Park, Y.; Kim, J.; Shin, Y.; Kim, S.; Whang, K. Effect of dietary inclusion of Lactobacillus acidophilus ATCC 43121 on cholesterol metabolism in rats. J. Microbiol. Biotechnol. 2007, 17, 655-662.

73. Xie, N.; Cui, Y.; Yin, Y.; Zhao, X.; Yang, J.; Wang, Z.; Fu, N.; Tang, Y.; Wang, X.; Liu, X.; et al. Effects of two Lactobacillus strains on lipid metabolism and intestinal microflora in rats fed a high-cholesterol diet. BMC Complementary Altern. Med. $2011,11$. [CrossRef] 